\title{
Regulation of excitation-contraction coupling in mouse cardiac myocytes: integrative analysis with mathematical modelling

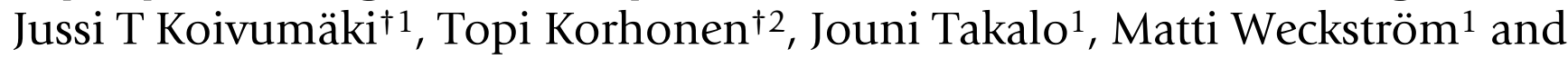 Pasi Tavi*2
}

\author{
Address: ${ }^{1}$ Department of Physics, University of Oulu \& Biocenter Oulu, Finland and ${ }^{2}$ Department of Biotechnology and Molecular Medicine, A.I. \\ Virtanen Institute for Molecular Sciences, University of Kuopio, Kuopio, Finland \\ Email: Jussi T Koivumäki - jussi.koivumaki@oulu.fi; Topi Korhonen - topi.korhonen@uku.fi; Jouni Takalo - jouni.takalo@oulu.fi; \\ Matti Weckström - matti.weckstrom@oulu.fi; Pasi Tavi* - pasi.tavi@uku.fi \\ * Corresponding author †Equal contributors
}

Published: 31 August 2009

BMC Physiology 2009, 9:16 doi:10.1186/1472-6793-9-16
Received: 25 June 2009

Accepted: 31 August 2009

This article is available from: http://www.biomedcentral.com/1472-6793/9/16

(c) 2009 Koivumäki et al; licensee BioMed Central Ltd.

This is an Open Access article distributed under the terms of the Creative Commons Attribution License (http://creativecommons.org/licenses/by/2.0), which permits unrestricted use, distribution, and reproduction in any medium, provided the original work is properly cited.

\begin{abstract}
Background: The cardiomyocyte is a prime example of inherently complex biological system with inter- and cross-connected feedback loops in signalling, forming the basic properties of intracellular homeostasis. Functional properties of cells and tissues have been studied e.g. with powerful tools of genetic engineering, combined with extensive experimentation. While this approach provides accurate information about the physiology at the endpoint, complementary methods, such as mathematical modelling, can provide more detailed information about the processes that have lead to the endpoint phenotype.
\end{abstract}

Results: In order to gain novel mechanistic information of the excitation-contraction coupling in normal myocytes and to analyze sophisticated genetically engineered heart models, we have built a mathematical model of a mouse ventricular myocyte. In addition to the fundamental components of membrane excitation, calcium signalling and contraction, our integrated model includes the calcium-calmodulin-dependent enzyme cascade and the regulation it imposes on the proteins involved in excitation-contraction coupling. With the model, we investigate the effects of three genetic modifications that interfere with calcium signalling: I) ablation of phospholamban, 2) disruption of the regulation of L-type calcium channels by calcium-calmodulin-dependent kinase II (CaMK) and 3) overexpression of CaMK. We show that the key features of the experimental phenotypes involve physiological compensatory and autoregulatory mechanisms that bring the system to a state closer to the original wild-type phenotype in all transgenic models. A drastic phenotype was found when the genetic modification disrupts the regulatory signalling system itself, i.e. the CaMK overexpression model.

Conclusion: The novel features of the presented cardiomyocyte model enable accurate description of excitation-contraction coupling. The model is thus an applicable tool for further studies of both normal and defective cellular physiology. We propose that integrative modelling as in the present work is a valuable complement to experiments in understanding the causality within complex biological systems such as cardiac myocytes. 


\section{Background}

The function of the mammalian heart depends essentially on the properties of individual heart muscle cells, i.e. cardiac myocytes. The complex chain of events that links action potential (AP) with contraction, known as excitation-contraction (E-C) coupling (for review see [1]), starts with myocyte membrane depolarization followed by opening of the voltage-gated L-type calcium channels (LCC) during the AP. This results in a $\mathrm{Ca}^{2+}$ influx through the sarcolemma, which activates $\mathrm{Ca}^{2+}$ release channels (the ryanodine receptors; RyRs) located in the junctional face of the sarcoplasmic reticulum (SR), and thereby induces calcium release from the SR (the calcium-induced calcium release; CICR). The resulting transient increase of the myoplasmic $\left[\mathrm{Ca}^{2+}\right]_{i}$ allows calcium binding to proteins of the contractile element that generate force and movement by utilizing the energy stored in the highenergy phosphate bonds of ATP. In order to avoid cumulative gain of $\mathrm{Ca}^{2+}$ in the cytosol and for relaxation to occur, SR $\mathrm{Ca}^{2+}{ }^{2+A T P a s e}$ (SERCA) pumps $\mathrm{Ca}^{2+}$ ions back into the SR to be released upon the next excitation, while the electrogenic $\mathrm{Na}^{+} / \mathrm{Ca}^{2+}$-exchanger (NCX) transports part of the released $\mathrm{Ca}^{2+}$ out of the cell.

The dynamic regulation of the calcium transport mechanisms is essential at varying heart beating rates. To fulfil this task, the same cellular calcium signals that control the contraction are also decoded by calcium-dependent enzymes, like the $\mathrm{Ca}^{2+}{ }^{2+}$-almodulin dependent kinases and phosphatases. These enzymes regulate the proteins involved in E-C coupling, providing physiologically important feedback mechanisms [2]. Since the same enzymes regulate nuclear gene expression during long term alterations in the calcium signals, they thus regulate differentiation, growth, metabolic and functional specializations, and eventually shape the phenotype of the muscle cells during development and pathogenesis $[3,4]$. A line of evidence suggests that the causes of heart failure involve defects in the regulation of cellular calcium and a concomitant reduction in cardiomyocyte contraction [5]. To elucidate the $\mathrm{E}-\mathrm{C}$ coupling processes involved in these pathological developments, a number of genetically engineered mouse models have been generated and studied experimentally. These models include, among others, genetic ablation or overexpression of the E-C coupling machinery proteins $[6,7]$ as well as transgenic overexpression of the regulative calcium activated enzymes $[8,9]$. The effects genetic interventions have on the function of the mouse E-C coupling machinery have been evaluated on the basis of the analysis of the phenotypes of the animals bearing the genetic modifications. These analyses have included measurements of morphological, histological and biochemical variables from mice hearts, and also biophysical and physiological analysis of the E-C coupling at the level of individual myocytes. This approach delivers precise data about the physiology at the endpoint, but in order to elucidate the processes that have lead to the endpoint phenotype it might be beneficial to use complementary tools, such as mathematical modelling.

To gain more mechanistic information from the signalling networks involved in cardiac $\mathrm{E}-\mathrm{C}$ coupling and from the sophisticated genetically engineered mouse models, we have built a mathematical model of mouse cardiomyocyte function. In addition to the fundamental components of E-C coupling, contraction and membrane excitability, this integrated model also includes the $\mathrm{Ca}^{2+}$-calmodulindependent kinase II (CaMK) cascade and its modulatory effects on the proteins involved in E-C coupling. CaMK regulates the activity of ryanodine receptors [10], SERCA [11] and its regulative protein PLB $[12,13]$ and L-type $\mathrm{Ca}^{2+}$-channels $[14,15]$. Because CaMK is activated by an increase in the cytosolic $\left[\mathrm{Ca}^{2+}\right]_{i}$ and, specifically, by the frequency of intracellular calcium transients $[16,17]$, it constitutes a physiological feedback mechanism adjusting calcium signals to the current heart rate [18]. Importantly, although the presented model is highly simplified, it is complex enough to be robust and to have features that arise from the signalling networks rather than from the properties of individual components.

The developed model simulates the dynamic behaviour of cardiomyocytes with beating frequency-dependent adaptations in function of the E-C coupling proteins as one of the fundamental physiological features. It can be argued that the model is thus an applicable and powerful tool for the reproduction of genetic cardiomyocyte modifications and analysis of the resulting cellular signalling changes in silico. To establish this, we have used the model to mathematically produce three different genetically modified mouse cardiac myocytes: 1) cardiomyocytes with deleted SERCA inhibitory protein phospholamban (PLB) [19], 2) disruption of the CaMK-dependent regulation of LCC, and 3) heart failure model induced by overexpression of CaMK [20]. Our results not only reveal unexpected changes in cardiomyocyte function upon changes of the functions of single proteins, but also demonstrate that mathematical modelling is an essential tool in designing genetically modified mice models as well as exploring the cellular signalling cascades of the existing models.

\section{Results}

\section{Features and Validation of the Model}

Our goal was to develop (see Methods section for details) a modelling tool with which we could simulate the key physiological aspects of the cardiac myocytes (Figure 1). The signals that the model produces are in line with the parameters from the experiments from mouse cardiac myocytes. Action potential features as well as resting potential values correspond to those reported previously 
(Table 1). Also, the model has accurate relative contributions of different calcium transport mechanisms that cooperatively generate calcium signals with parameters like diastolic and systolic $\left[\mathrm{Ca}^{2+}\right]_{i}$ as well as decays of calcium transients corresponding to the measured average values from various sources (Table 2). The variation among the published experimental results is surprisingly large (Figure 2B and 2C, and Table 2), probably due to differences in the experimentation and treatment of the cardiomyocytes. Therefore, it is not reasonable to tune the model parameters exactly to any single set of experimental results. More importantly, in order to verify the model we focused on the physiological behaviour of the variables and their trends during the intervention experiments. As an example of this, the model could successfully predict the behaviour of the experimentally observed diastolic [21-23] and systolic $\left[\mathrm{Ca}^{2+}\right]_{\mathrm{i}}$ around 1-4 Hz (Figure 2B). In the experiments, a commonly used intervention to study the capacity of the intracellular calcium stores is the caffeine pulse experiment, where rapid application of caffeine empties the SR abruptly and produces a cytosolic calcium rise, the height of which corresponds to the amount of calcium stored in the SR. During the caffeine pulse, the calcium extrusion depends mainly on the NCX, and therefore the decay of the $\left[\mathrm{Ca}^{2+}\right]_{i}$ can be used to estimate the amount and activity of NCX in the given cell. We simulated a caffeine pulse experiment and compared the results to the in vivo data of Maier et al. [20] and Li et al. [19]. The amplitude of the simulated caffeine-induced intracellular calcium transient agreed well with the measurements. Also the decay constants of $\left[\mathrm{Ca}^{2+}\right]_{\mathrm{i}}$ are of the same magnitude, $2.5 \pm 0.3 \mathrm{~s}, 2.2 \pm 0.2 \mathrm{~s}$, and $1.8 \pm 0.03 \mathrm{~s}$ for $[20,19]$ and the model simulations, respectively. Therefore, the model fulfilled the criteria of being capable of reproducing real physiological phenomena, like the $\left[\mathrm{Ca}^{2+}\right]_{\mathrm{i}}$-frequency curve, and could robustly simulate the caffeine pulse experiment.

To further evaluate the model features, we did a series of simulations aimed to characterize the frequency-dependent changes in the model outputs (Figure 3). Simulations were started from a steady-state (pacing at $0.5 \mathrm{~Hz}$ ) and the pacing frequency was increased with six second intervals to $1,2,3$, and $4 \mathrm{~Hz}$. These simulations demonstrate a fundamental feature of the E-C coupling regulation. While the frequency-dependent changes at the level of activity of individual proteins are small, like the change in the L-type calcium current (Figure 3, left upper panel), the sum of these effects is manifested as an order of greater changes in the calcium signals. The calcium transients became smaller as a function of pacing frequency at the same time when the diastolic $[\mathrm{Ca} 2+] \mathrm{i}$ rose. This shows that even though CaMK increases the activity of the SERCA, it cannot fully compensate for the frequent SR calcium releases with such a short timescale of adaptation (six second intervals). Therefore, both the stored (network sarcoplasmic reticulum; NSR) and releasable (junctional SR; JSR) pools of calcium in the SR are partially depleted, which reduces the SR calcium release while the extra calcium builds up the cytosolic [Ca2+]i, just like in isolated mouse ventricular myocytes $[24,25]$. The rise in the diastolic $[\mathrm{Ca} 2+] \mathrm{i}$, on the other hand increases the diastolic outward NCX current (Figure 3), which causes a small hyperpolarisation of the resting potential from $-79.3 \mathrm{mV}$ at $0.5 \mathrm{~Hz}$ to $-80.4 \mathrm{mV}$ at $4 \mathrm{~Hz}$.

As expected, the activity of both CaMK and CaN increases with the pacing frequency from $0.5 \mathrm{~Hz}$ to $4 \mathrm{~Hz}$. According to the activation characteristics of $\mathrm{CaN}$, its activity increases the most at pacing frequencies from 0.5 to $2 \mathrm{~Hz}$ and starts to saturate at higher frequencies (Figure 3). CaMK, on the other hand, is activated predominantly at frequencies higher than $2 \mathrm{~Hz}$. This feature is identical to the biphasic synaptic plasticity in neurons explained by a model including inhibition of calcium activated CaMK upon co-activated calcineurin [26]. The divergent frequency dependence of $\mathrm{CaMK}$ and $\mathrm{CaN}$ is highlighted in comparison of the pacing steady-state activities (Figure 4). The difference in the ranges of $\mathrm{CaN}$ and CaMK activation is even more evident, when the pacing-dependent enzyme levels are scaled to the theoretical upper limit that can be induced with a maximal calcium stimulus (Figure 4, inset).

Table I: Comparison of the AP properties of the model and experimental data

\begin{tabular}{|c|c|c|}
\hline Magnitude & Simulated value & Experimental value \\
\hline Quiescent $\left[\mathrm{Na}^{+}\right]_{\mathrm{i}}(\mathrm{mM})$ & 13.6 & $16.4 \pm 0.7[66] ; \mid 15.6 \pm 0.7[66] ; 12.5 \pm 1.8[67]$ \\
\hline Quiescent $\left[\mathrm{K}^{+}\right]_{\mathrm{i}}(\mathrm{mM})$ & 143.0 & $\sim 40[8 \mid]$ \\
\hline Quiescent $\mathrm{E}_{\mathrm{K}}(\mathrm{mV})$ & -84.1 & $\sim-80[81]$ \\
\hline Quiescent $\vee(\mathrm{mV})$ & -79.0 & $\sim \mathrm{E}_{\mathrm{K}}[8 \mathrm{I}]$ \\
\hline AP amplitude $(\mathrm{mV})$ at I $\mathrm{Hz}$ & 110.6 & $106 \pm 11[20] ; 118[68]$ \\
\hline AP $50 \%$ duration $(\mathrm{ms})$ at $\mathrm{I} \mathrm{Hz}$ & 3.25 & $4.5 \pm 0.3[69] ; 2.6 \pm 0.1[59] ; 1.6 \pm 0.2[20]$ \\
\hline $\mathrm{dV} / \mathrm{dt}_{\max }(\mathrm{V} / \mathrm{s})$ at $\mathrm{I} \mathrm{Hz}$ & 148.4 & $\begin{array}{l}161 \pm 44 \text { (neonatal cell culture) }[70] \\
193.25 \pm 13.94 \text { (rat) }[7 \mid] ; 133.8 \pm 9.2 \text { (42 days old) }[58]\end{array}$ \\
\hline
\end{tabular}


Table 2: Comparison of $\mathrm{Ca}^{2+}$ handling properties of $\mathrm{E}-\mathrm{C}$ coupling in the developed model and experiments

\begin{tabular}{|c|c|c|}
\hline Magnitude & Simulated value & Experimental value \\
\hline Diastolic $\left[\mathrm{Ca}^{2+}\right]_{\mathrm{i}}(\mu \mathrm{M})$ & 0.10 & $0.100 \pm 0.012[66] ; 0.099 \pm 0.011[21] ; 0.200 \pm 0.021[20]$ \\
\hline Systolic $\left[\mathrm{Ca}^{2+}\right]_{\mathrm{i}}(\mu \mathrm{M})$ & 0.46 & $0.458 \pm 0.073[66] ; 0.314 \pm 0.028[21] ; 0.425 \pm 0.026[20]$ \\
\hline Decay constant of $\mathrm{Ca}^{2+}$ transient (ms) & 190 & $\begin{array}{l}166 \pm 12(0.25 \mathrm{~Hz})[66] ; 293 \pm 19[20] \\
188 \pm 14(0.5 \mathrm{~Hz})[19] ; 210(0.5 \mathrm{~Hz})[2]\end{array}$ \\
\hline $\int \mathrm{I}_{\mathrm{C}_{\mathrm{a}, L}} \mathrm{dt}(\mu \mathrm{M})$ & 1.0 & $1.5[22]$ \\
\hline Maximum J $J_{\text {REL }}(\mu \mathrm{mol} /$ Lcytosol/ms) & 2.2 & 3 (rat) $[72,81]$ \\
\hline Diastolic SR Ca ${ }^{2+}$ content $(\mu \mathrm{M})$ & 92 & $142 \pm 9[20] ; 102(0.5 \mathrm{~Hz})[19] ; 64.3 \pm 13.0(0.5 \mathrm{~Hz})[73]$ \\
\hline Fractional release $(\%)$ & 28 & $29 \pm 3[20]$ \\
\hline SERCA Ca ${ }^{2+}$ removal fraction (\%) & 89 & 88 [20]; $90.3(0.5 \mathrm{~Hz})$ [19]; $88(0.5 \mathrm{~Hz})[73]$ \\
\hline $\mathrm{NCX} \mathrm{Ca}^{2+}$ removal fraction (\%) & 10 & 12 [20]; $9.2(0.5 \mathrm{~Hz})[19] ; 12(0.5 \mathrm{~Hz})[73]$ \\
\hline Slow $\mathrm{Ca}^{2+}$ removal fraction (\%) & 0.56 & $0.5(0.5 \mathrm{~Hz})[19]$ \\
\hline $\operatorname{FDAR}\left(\tau_{1 \mathrm{~Hz}} / \tau_{4 \mathrm{~Hz}}\right)$ & 2.36 & $2.06 \pm 0.08\left(\tau_{0.5 \mathrm{~Hz}} / \tau_{4 \mathrm{~Hz}}\right)[20] ; 1.87 \pm 0.06\left(\tau_{1 \mathrm{~Hz}} / \tau_{5 \mathrm{~Hz}}\right)[74]$ \\
\hline
\end{tabular}

Simulation results are shown for I Hz pacing steady-state. All concentrations are in cytosol volume.

\section{Phospholamban Knockout Model}

The elegant cardiac PLB knockout (PLB-KO) mouse model has been used extensively to study the role of the $\mathrm{SR}$ in E-C coupling $[6,27,28]$. One of the rare features of the PLB-KO model among the genetically engineered cardiac mouse models is that the PLB-KO mice do not develop cardiac hypertrophy or failure [6]. PLB-KO can therefore be used in the physiological elucidation of the role of SR calcium uptake modulation via SERCA-PLB interactions as well as the role of SR calcium uptake and release in E-C coupling [12,29-31]. We wanted to test whether our simulations could reproduce the experimental results of this comprehensive mouse model and reveal possible signalling mechanisms that cannot be observed in experiments.

Total relief of PLB inhibition of SERCA has a great impact on the $\mathrm{Ca}^{2+}$ dynamics of the myocyte as demonstrated in Figure 5. The simulated results of WT and PLB-KO Ca'+ transients correspond well with the wild-type and knockout measurements of Huser et al. [32]. The comparison of $\mathrm{Ca}^{2+}$ transients in Figure 5A and 5B shows that the amplitude ratio of PLB-KO vs. WT is 1.6 in both the in vivo and the in silico experiments. It was previously reported that in the PLB-KO mouse, the ventricular cardiomyocytes have a decreased expression level of RyR [33]. We therefore implemented this modification into the model (see Methods for details). With RyR downregulation in the model, the amplitude of the $\mathrm{Ca}^{2+}$ transient is $12 \%$ smaller compared to pure phospholamban knock-out due to a reduced amount of calcium release units (Figure 5B). This might indicate that the general mechanism of the compensations is to attenuate the effect of initial modifications, i.e. to reduce the change in myocyte function.

As expected, the increased systolic $\mathrm{Ca}^{2+}$ concentration in PLB-KO causes a substantial rise in the activity of CaMK and $\mathrm{CaN}$ (Figure 5C). Compared to WT the mean activities of CaMK and CaN increase by 35\% and 102\% for PLB-
KO, and by $44 \%$ and $122 \%$ for PLB-KO* (knockout with no compensations) at $0.5 \mathrm{~Hz}$ pacing. Upon an increase in the pacing frequency, this difference becomes smaller. Increased amplitude of the $\mathrm{Ca}^{2+}$ transient increases the activity of SERCA both directly (increased systolic $\left[\mathrm{Ca}^{2+}\right]_{\mathrm{i}}$ ) and indirectly (via enzymatic regulation). As a result the decay time constants of the calcium transients decrease by 26\% (PLB-KO) and 28\% (PLB-KO*) compared to WT (Figure 5D), while the $\mathrm{Ca}^{2+}$ concentration in the $\mathrm{SR}$ $\left(\left[\mathrm{Ca}^{2+}\right]_{\mathrm{SR}}\right)$ increases by $\sim 100 \%$ in both PLB-KO versions (Figure 5E), which is in line with experimental findings [33].

The increased CaMK activity in the PLB knockout naturally affects the function of LCC as well. Surprisingly, in the simulations the peak value of $I_{C a, L}$ is actually reduced by $3 \%$ in PLB-KO vs. WT simulations for $0.5 \mathrm{~Hz}$ pacing. This results from the fact that PLB-KO myocytes have enhanced calcium release due to higher $\left[\mathrm{Ca}^{2+}\right]_{\mathrm{SR}}$ and increased CaMK phosphorylation of RyR. This $\approx 2$-fold increase in $\mathrm{J}_{\text {rel }}$ brings more calcium to the vicinity of the LCCs, thus causing a faster inactivation of the channels. This mechanism has been observed also in experiments [34] and explains elegantly how the complex system controls itself to cope with the changed functional environment.

The overall change in the in silico PLB-KO phenotype corresponds very well with in vivo results and is rather straightforward, i.e. due to the increased SERCA activity the relaxation of the myocyte is accelerated significantly (Figure 5D). This advantage, however, falls short compared to the physiologically more relevant phenomena. The force-frequency relation (FFR) is reversed: $\Delta\left(F_{4 \mathrm{~Hz}}-F_{1}\right.$ $\mathrm{Hz}$ ) value is $+43 \%$ and $-20 \%$ in WT and PLB-KO simulations, respectively. Frequency-dependent acceleration of relaxation (FDAR) is also blunted in the PLB knockout myocytes: the $0.5 \mathrm{~Hz} / 4 \mathrm{~Hz}$ ratio of calcium transient decay is reduced from 3.5 to 2.3 for WT vs. PLB-KO. However, 


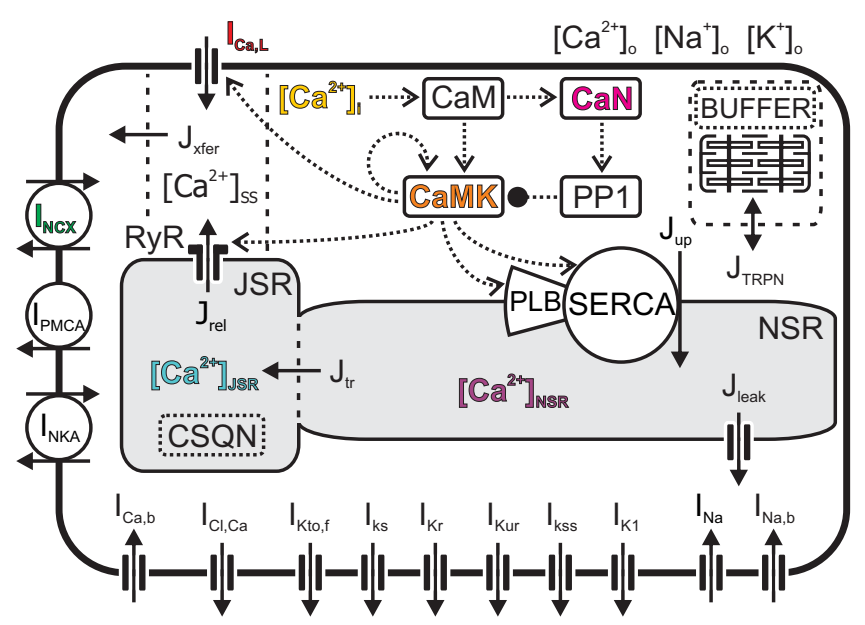

Figure I

Schematic presentation of the components and features of the model. Model accounts for processes that regulate intracellular concentration changes of sodium, potassium and calcium ions. The $\mathrm{Ca}^{2+}$ transport mechanisms are the L-type $\mathrm{Ca}^{2+}$ current $\left(\mathrm{I}_{\mathrm{Ca}, \mathrm{L}}\right)$, ryanodine receptor (RyR), SR Ca ${ }^{2+}$ ATPase (SERCA), sarcolemmal $\mathrm{Na}^{+} / \mathrm{Ca}^{2+}$ exchanger (NCX), sarcolemmal $\mathrm{Ca}^{2+}$ ATPase (PMCA), and background $\mathrm{Ca}^{2+}$ current $\left(\mathrm{I}_{\mathrm{Ca}} \mathrm{b}\right)$. The $\mathrm{Ca}^{2+}$ fluxes within the cell are the uptake of $\left.\mathrm{Ca}^{2+}()_{\text {up }}\right)$ from the cytosol to the network sarcoplasmic reticulum (NSR), $\mathrm{Ca}^{2+}$ release $\left(\mathrm{U}_{\text {rel }}\right)$ from the junctional SR (JSR), $\mathrm{Ca}^{2+}$ flux $\left(\mathrm{J}_{\mathrm{tr}}\right.$ ) from the NSR to JSR, $\mathrm{Ca}^{2+}$ leak $\left(J_{\text {leak }}\right)$ from the NSR to the cytosol, $\mathrm{Ca}^{2+}$ flux from the subspace (SS) volume to the bulk myoplasm $\left(\mathrm{J}_{x \mathrm{fer}}\right.$ ) and from the cytosol to Troponin ( $\mathrm{JTRPN}_{\text {TRN }}$ ). The cytosolic bulk $\mathrm{Ca}^{2+}$ concentration is $\left[\mathrm{Ca}^{2+}\right]_{\mathrm{i}}$. The calcium concentrations in the SS, JSR and NSR compartments are $\left[\mathrm{Ca}^{2+}\right]_{S S},\left[\mathrm{Ca}^{2+}\right]_{S R}$ and $\left[\mathrm{Ca}^{2+}\right]_{\mathrm{NSR}}$, respectively. The $\mathrm{Ca}^{2+}$ buffers that operate in the JSR and related to TRPN are presented as CSQN and BUFFER, respectively. The input for the enzyme reactions is the intracellular cytosolic $\mathrm{Ca}^{2+}$ concentration, $\left[\mathrm{Ca}^{2+}\right]_{\mathrm{i}}$. A rise in the $\left[\mathrm{Ca}^{2+}\right]_{i}$ level increases $\mathrm{Ca}^{2+}$ binding to calmodulin (CaM), which in turn phosphorylates more $\mathrm{Ca}^{2+} / \mathrm{calmodulin}$-dependent protein kinase II (CaMK) and calcineurin $(\mathrm{CaN})$. Phosphorylation of the latter induces phosphorylation of protein phosphatase I (PPI). The autophosphorylation of CaMK is presented as a positive feedback loop and PPI inhibition as a negative feedback. The model also includes the following transmembrane currents: the $\mathrm{Ca}^{2+}$-activated chloride $\left(\mathrm{Cl}^{-}\right)$ current $\left(\mathrm{I}_{\mathrm{Cl}}, \mathrm{Ca}_{\mathrm{a}}\right)$, the rapidly recovering transient outward $\mathrm{K}^{+}$ current $\left(I_{K_{\text {to }, f}}\right)$, the slow delayed rectifier $\mathrm{K}^{+}$current $\left(\mathrm{I}_{\mathrm{Ks}}\right)$, the rapid delayed rectifier $\mathrm{K}^{+}$current $\left(\mathrm{I}_{\mathrm{Kr}}\right)$, the ultrarapidly activating delayed rectifier $\mathrm{K}^{+}$current $\left(\mathrm{I}_{\mathrm{Kur}}\right)$, noninactivating steady-state voltage activated $\mathrm{K}^{+}$current $\left(\mathrm{I}_{\mathrm{Kss}}\right)$, the time-independent $\mathrm{K}^{+}$current $\left(\mathrm{I}_{\mathrm{KI}}\right)$, fast $\mathrm{Na}^{+}$current $\left(\mathrm{I}_{\mathrm{Na}}\right), \mathrm{Na}^{+}$background current $\left(\mathrm{I}_{\mathrm{Na}, \mathrm{b}}\right)$, and the $\mathrm{Na}^{+} / \mathrm{K}^{+}$pump $\left(\mathrm{I}_{\mathrm{NKA}}\right)$.

while the physiological adaptation to increased pacing is impaired, the function of the myocytes is in fact improved; the PLB-KO just recruits the contractile reserve at lower frequencies.

\section{Transgenic Model of CaMK-Dependent Regulation of L- type Calcium Channel}

In order to find out how the function of the cardiac myocyte would change when the CaMK-dependent regulation is switched off, we implemented a transgenic version of the model, in which the modulation of LCC is disrupted either by blocking the phosphorylation (bLCC) or setting the phosphorylation site constitutively active (cLCC); see Methods section for details of implementation. The experimental results indicate that the activation of CaMK promotes longer openings of the L-type calcium channels $[14]$. At the level of the whole cardiomyocyte, this manifests as slower inactivation and increased peak of the $\mathrm{I}_{\mathrm{Ca} \text {, }}$ current [35]; a phenomenon referred to as "facilitation".

According to simulations, the disrupted CaMK-dependent modulation of LCC changes the frequency-dependence of $\mathrm{I}_{\mathrm{Ca}, \mathrm{L}}$ (Figure 6A). The maximum deviation of the amplitude of $\mathrm{I}_{\mathrm{Ca}} \mathrm{L}$ from WT is $-4.3 \%$ (at $4 \mathrm{~Hz}$ ) and $+7.5 \%$ (at 0.5 $\mathrm{Hz}$ ) for bLCC and CLCC, respectively. The contractile force, which can be considered as a characteristic output of the end-point phenotype, is affected only to a very small extent (Figure 6C). The inset of Figure 6C further indicates that the dynamics of the force are not drastically affected. That is, the main changing variable is the amplitude of the force, whereas, the baseline tension, time-topeak-force and relaxation time remain practically constant compared to WT. As one could expect for a short action potential animal such as the mouse, the AP duration (at $90 \%$ repolarization) is virtually unaltered between the transgenic and wild-type models (Figure 6B).

The increased (in cLCC) and decreased (in bLCC) $\mathrm{I}_{\mathrm{Ca}, \mathrm{L}}$ should lead to accumulation and depletion of intracellular calcium, respectively. In the simulation results, this is seen as altered SR calcium content (Figure 6D) and consequent changes in the integral of $\mathrm{J}_{\text {rel }}$ (Figure 6E). These two parameters behave differently in function of the pacing frequency. While the deviation of bLCC from WT is parallel to the changes of $\mathrm{I}_{\mathrm{Ca}, \mathrm{L}}$ (Figure $6 \mathrm{E}$ ), the difference between CLCC and WT is more pronounced in the integral of $\mathrm{J}_{\mathrm{rel}}$. This is due to the fact that calcium release from the SR is affected not only by the increased SR calcium content but also by the enhanced trigger, i.e. $\mathrm{I}_{\mathrm{Ca}, \mathrm{L}}$.

Intuitively, the changes in the calcium current should perhaps lead to more significant changes in the E-C coupling, since LCC is one of the main components of cellular calcium transport machinery. Furthermore, the strong coupling of $\left[\mathrm{Ca}^{2+}\right]_{\mathrm{i}}$ and CaMK activation, decreased in bLCC and increased in CLCC, should work to enhance those alterations due to consequent changes in the phosphorylation of the other CaMK targets RyR and SERCA. This scenario is, however, affected by another regulatory loop. In the bLCC case, decreased $\mathrm{I}_{\mathrm{Ca}, \mathrm{L}}$ leads to decreased $\mathrm{J}_{\text {rel }}$, 
A

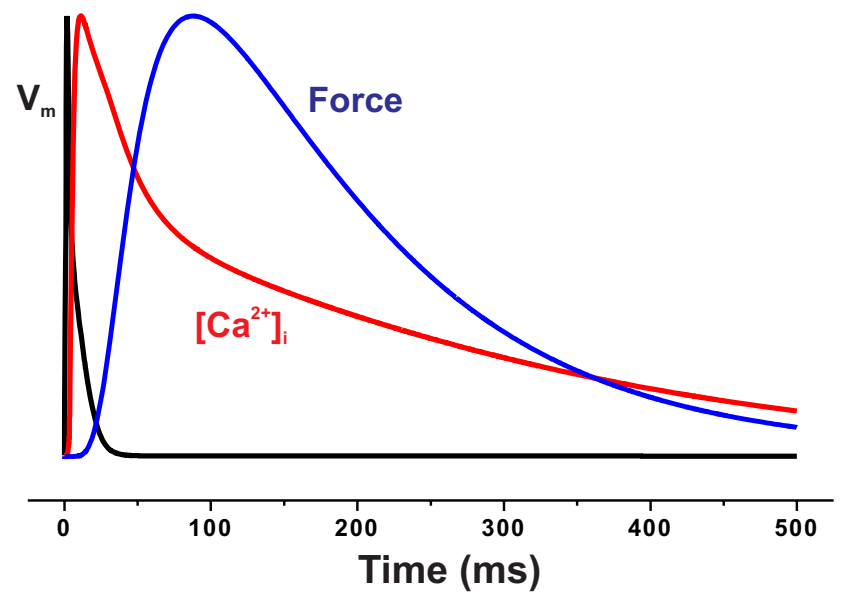

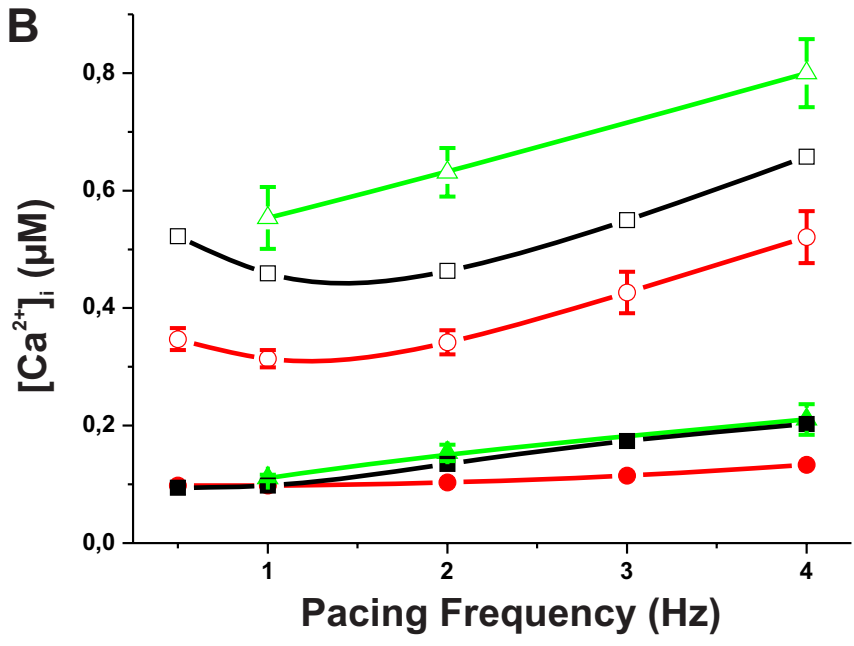

C

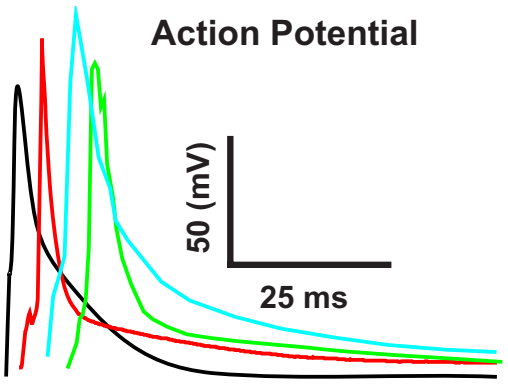

D

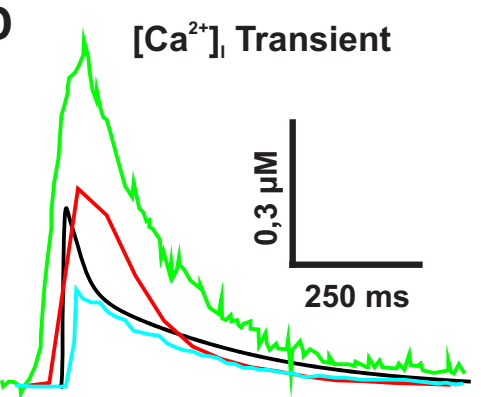

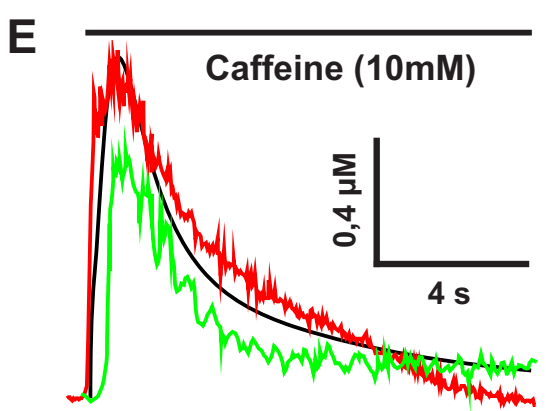

Figure 2

Validation of the model characteristics. (A) Normalized action potential $\left(\mathrm{V}_{\mathrm{m}}\right),\left[\mathrm{Ca}^{2+}\right]_{\mathrm{i}}$ transient and force amplitude at I $\mathrm{Hz}$ pacing. (B) Diastolic (closed symbols) and systolic (open symbols) $\left[\mathrm{Ca}^{2+}\right]_{\mathrm{i}}$ values as a function of pacing frequency. Simulated values (black squares) are compared with the experimental results of lto et al. [2I] (red circles) and Antoons et al. [57](green triangles). The model was able to successfully reproduce the experimentally observed minimum in the systolic [Ca $\left.{ }^{2+}\right]_{i}$ around I-2 Hz [2I]. (C) Simulated (black) action potential (AP) is compared to measurements by Guo et al. [58] (red), Brunet et al. [59] (green) and Petrashevskaya et al. [60] (cyan). The comparison of recorded and simulated APs (note that the APs have been shifted in time for comparison) demonstrates a good qualitative agreement with the experiments. (D) $\left[\mathrm{Ca}^{2+}\right]_{\mathrm{i}}$ transient at I $\mathrm{Hz}$ pacing. Comparison of simulated results (black) to the experimental data of Williams et al. [6I] (red), Maeir et al. [20] (green) and Huser et al. [32] (cyan) demonstrates a good qualitative agreement of in silico and largely variated in vivo data. (E) Caffeine-induced $\left[\mathrm{Ca}^{2+}\right]_{i}$ transients. The amplitude and decay time constants of simulated data (black) are of the same magnitude with the in vivo results of Maeir et al. [20] (red) and Li et al. [19] (green).

which reduces the calcium-dependent inactivation of LCC; a chain of events that affects the intracellular calcium dynamics in the opposite direction in cLCC. Thus, in both cases this autoregulation would tend to reduce the original effect of altered $\mathrm{I}_{\mathrm{Ca}, \mathrm{L}}$. To demonstrate this, we calculated what the inactivation of LCC would be in the transgenic models if all the other parameters were identical to WT (Figure 6F; dashed lines); see Methods section for details of this acute TG. This shows that with the feedback systems present, the autoregulation mechanisms bring the system closer to WT behaviour. Thus, a change in one physiological regulatory event, in this case the disrupted modulation of the LCC, cannot easily induce drastic changes to the overall function of the myocyte.

\section{CaMK Overexpression Model}

CaMK has a substantial role in the E-C coupling of both the normal and the failing heart [36-39]. Cardiac overexpression of the cytosolic isoform of CaMK results in cardiac hypertrophy and a unique phenotype of the myocytes [20]. The phenotype resulted from the initial modification ( $3 \times$ increase in the CaMK expression), but also from a variety of significant changes in the expressions of E-C coupling proteins, like SERCA, RyR and NCX [20]; see Methods for details. To elucidate the relative contribution of these two mechanisms, i.e., the CaMK overexpression and the compensatory changes, we implemented two versions of the in silico model. The first one (CaMK3X) simulates the experimentally observed pheno- 
$\mathbf{f}(\mathbf{H z})$
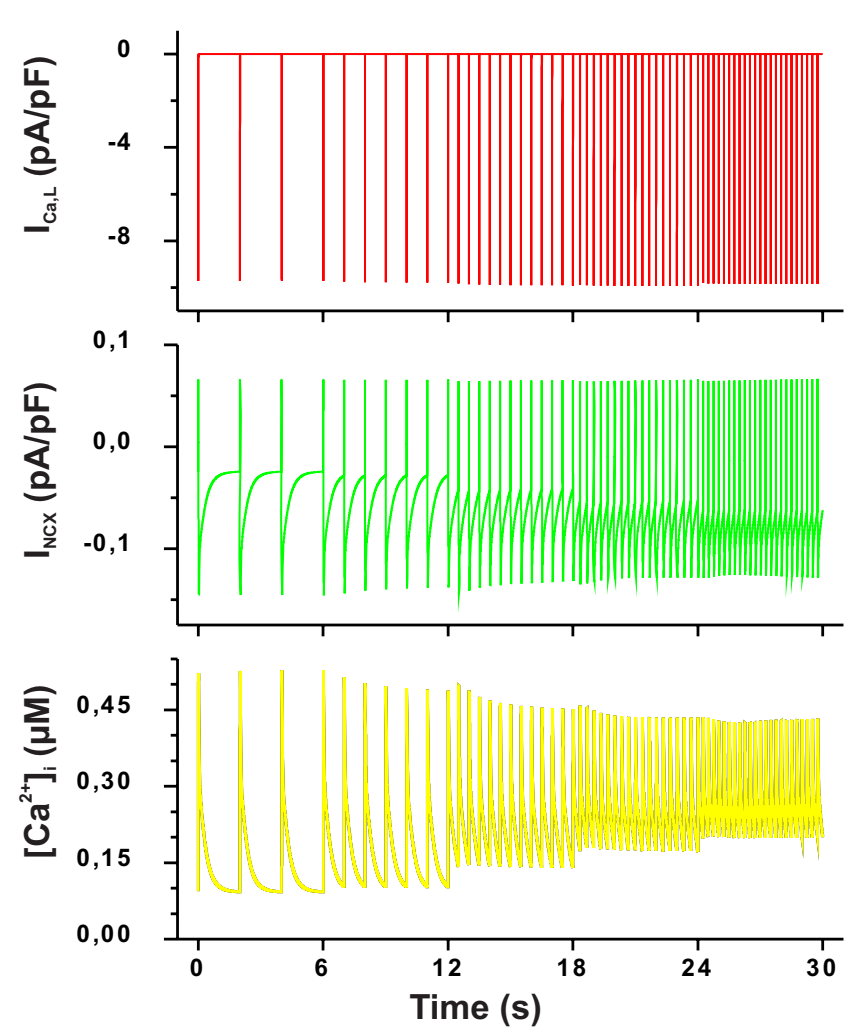

\begin{tabular}{|l|l|l|l|l|l|}
$\mathrm{f}(\mathrm{Hz})$ & 0,5 & 1 & 2 & 3 & 4 \\
\hline
\end{tabular}

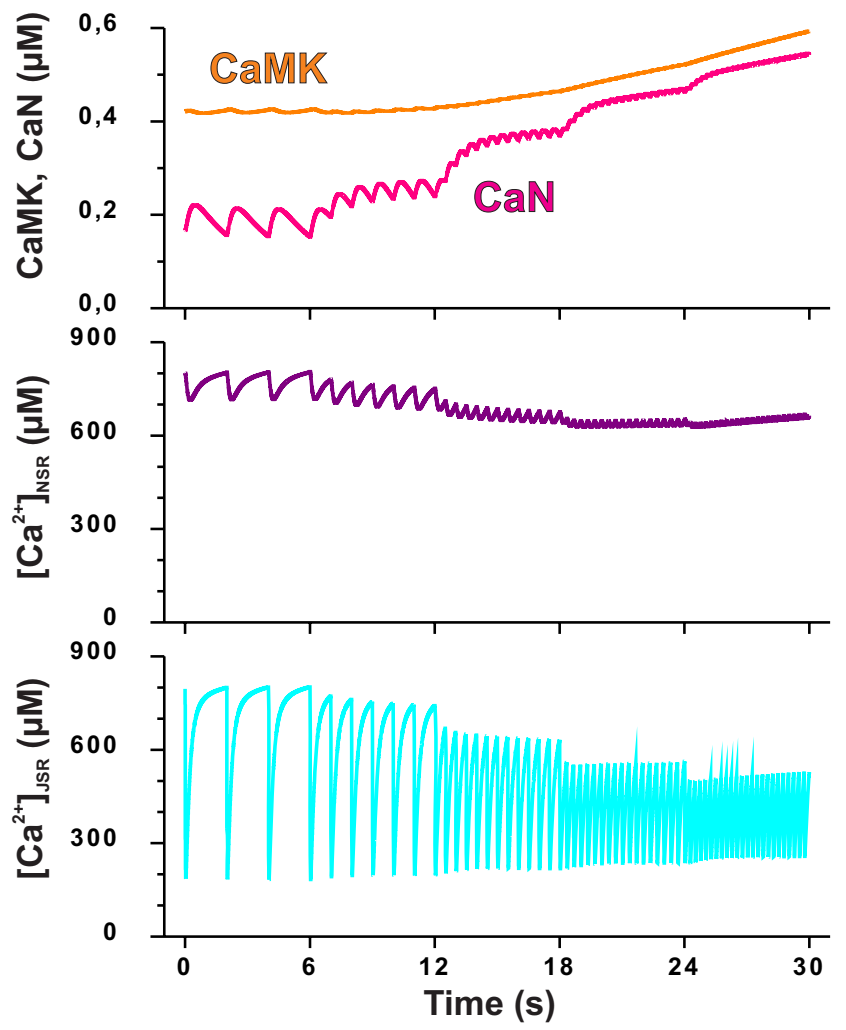

Figure 3

Examples of outputs (colour coding matches Figure I) during a dynamic in silico pacing experiment. The simulation series was started from a steady-state (pacing at $0.5 \mathrm{~Hz}$ ) and the pacing frequency was increased with six second intervals to $\mathrm{I}, 2,3$, and $4 \mathrm{~Hz}$. Left panel shows the L-type calcium current $\left(\mathrm{I}_{\mathrm{Ca}, \mathrm{L}}\right)$, sodium calcium exchanger current $\left(\mathrm{I}_{\mathrm{NCX}}\right)$, and calcium concentration in the cytosol $\left(\left[\mathrm{Ca}^{2+}\right]_{\mathrm{i}}\right)$. Whereas the peak amplitude of $\mathrm{I}_{\mathrm{Ca}} \mathrm{L}$ is hardly changed, the calcium transients become smaller as the pacing frequency increases, because the sarcoplasmic reticulum (SR) $\mathrm{Ca}^{2+}$ stores are reduced. At the same time, the rise of the diastolic $\left[\mathrm{Ca}^{2+}\right]_{i}$ causes an increase in the diastolic outward $\mathrm{I}_{\mathrm{NCX}}$. In the right panel, the concentration of active calcineurin $(\mathrm{CaN})$ and $\mathrm{Ca}^{2+} /$ calmodulin-dependent protein kinase II (CaMK), as well as the calcium concentration in the network SR $\left(\mathrm{Ca}_{S R}\right)$ and in the junctional SR $\left(\mathrm{Ca}_{N S R}\right)$, are presented from the same incremental simulation. The CaN curve follows the $\mathrm{Ca}^{2+}$ transients more closely, in fact oscillating clearly at the lowest pacing frequencies, whereas CaMK activity displays a stronger integrative aspect and, accordingly, a much smoother time-course.

type and the second one $\left(\mathrm{CaMK} 3 \mathrm{X}^{*}\right)$ a theoretical situation, where there are no compensations at the level of gene expression (implementation scheme can be found in Methods).

When the total amount of CaMK was increased $3 \times$ corresponding to the level of the CaMK in the CaMK-TG cardiomyocytes, the amount of active CaMK was changed dramatically at any given pacing frequency in the model (Figure 6A). At $1 \mathrm{~Hz}$ pacing, CaMK activities were 2.5 and 4.3 times higher than WT in the CaMK3X and the CaMK3X*, respectively. When CaMK activity is forced to such a high level, increased phosphorylation of CaMK targets should increase the calcium influx (via LCC), and increase SR calcium uptake (via PLB and SERCA) and release (via RyR), which together should increase the calcium signals dramatically. Therefore the reported CaMKTG mouse cardiomyocyte phenotype seems counterintuitive, because TG myocytes have dramatically decreased $\mathrm{Ca}^{2+}$ transient amplitudes (Figure 7B). Contrary to this, the model predicts that $\mathrm{CaMK}$ overexpression alone (CaMK3X*) increases the calcium transient amplitude by $117 \%$, and contraction force by $126 \%$ (Figure 7C), while the calcium transient decay $\left(\tau_{\mathrm{Ca}}\right)$ decreases simultaneously by $41 \%$ compared to WT at $1 \mathrm{~Hz}$ (Figure 7D).

At the level of cytosolic calcium signals and contraction, these changes are qualitatively almost identical to those induced by deletion of PLB (Figure 5B). However, while the compensations in PLB-KO myocytes are minute and 


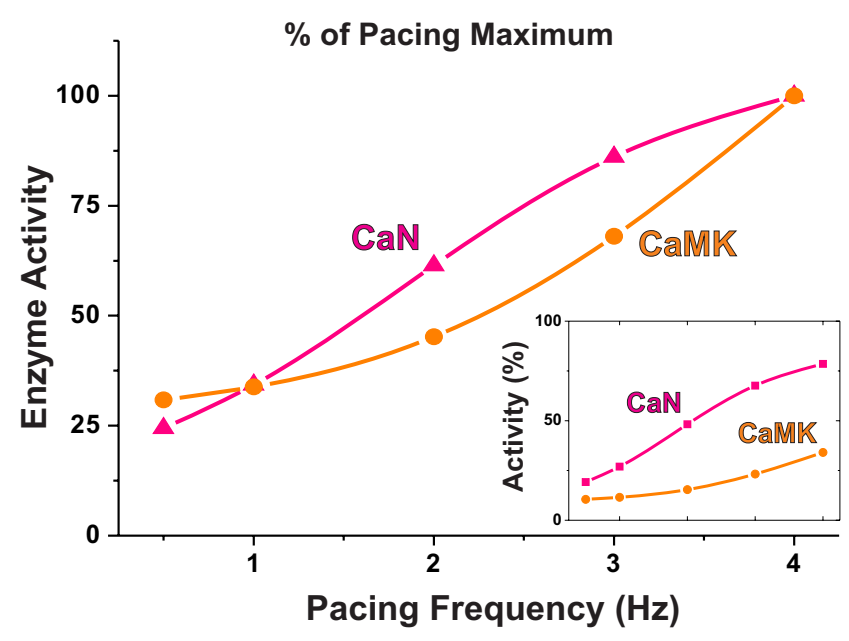

Figure 4

The simulated concentrations of active $\mathrm{CaN}$ and CaMK (colour coding matches Figure I). The enzyme activities at pacing steady-state are shown in relation to the maximum pacing-induced value (at $4 \mathrm{~Hz}$ ). The divergent pacing dependence of calcineurin $(\mathrm{CaN})$ and $\mathrm{Ca}^{2+} /$ calmodulindependent protein kinase II (CaMK) is demonstrated even more clearly in the inset, which shows the enzyme activities scaled to the maximum calcium-induced value.

the phenotype is mainly due to ablation of PLB, the CaMK-TG phenotype seems to be induced mostly by secondary changes in gene expression. That is, when the documented changes in the protein levels of CaMK-TG myocytes were implemented into the model, the amplitude of the simulated calcium transients decreased by $62 \%$ and the contraction force by $90 \%$ at $1 \mathrm{~Hz}$ pacing compared to the WT model. Quite naturally the smaller calcium signals also affect the amount of calcium activated CaMK, which is reduced by $41 \%$ compared to the CaMK3X*. Again this demonstrates a general feature of biological feedback loops, where secondary modifications tend to reduce the strength of the initial stimulus. Despite the dramatically increased CaMK phosphorylation, which promotes activation of RyR, the amount of calcium released from the SR is significantly smaller (55\% decrease at $1 \mathrm{~Hz}$ pacing) in the CaMK3X (Figure 7E). Thus, the reduction in the $\left[\mathrm{Ca}^{2+}\right]_{\mathrm{SR}}$ prevents an increase in calcium release $\left(\mathrm{J}_{\mathrm{rel}}\right)$. This conclusion is supported by the fact that the fractional release is reduced by $40 \%$ from 0.28 to 0.17 in silico.

In the model with CaMK overexpression and the reported changes in the protein levels, SR calcium content is reduced by $25 \%$ (data not shown). However, it was reported earlier that in vivo the reduction was 44\% [20]. To explain the prominent reduction of the SR calcium content, it was reported that the diastolic $\mathrm{Ca}^{2+}$ leak was increased 4 -fold in the TG vs. WT mice [20]. To account for this mechanism, we updated the model with a putative CaMK-dependent RyR leak (see Methods section for details), which produced $\mathrm{a} \approx 3$-fold increase in the resting $\mathrm{Ca}^{2+}$ leak for CaMK3X vs. WT (data not shown). When simulated together with the CaMK3X model version, the RyR leak did not induce a significant effect on the already depressed E-C coupling. We found that the SR $\mathrm{Ca}^{2+}$ content was reduced by $17 \%$ in the leaky CaMK3X compared to the non-leaky version, but the $\mathrm{Ca}^{2+}$ transient amplitude and contraction force were decreased only slightly (Figure 7F and 7G). According to the simulations, the WT in silico myocyte was not affected to a large extent by the leakiness either.

When leaky RyRs were simulated together with the acute effect of CaMK overexpression (CaMK3X*), calcium signalling was drastically changed. As expected, upon an increase in the RyR leak, the SR calcium content was decreased by $38 \%$ (at $1 \mathrm{~Hz}$ ), leading to reduced SR calcium release and subsequently smaller calcium transients (Figure 7C). However, it is quite unexpected that according to simulations the RyR leak might have some beneficial effects on the function of cardiomyocytes facing an acute increase in CaMK activity. While limiting the increase in the calcium transient amplitude, the RyR leak enhances the calcium transient decay (Figure 7D) and, more importantly, restores the positive trend of the forcefrequency-relationship (Figure 7F and 7G). The physiological adaptation to an increase in the contraction rate is thus re-established. This data is qualitatively in line with the results from a robust acute overexpression of CaMK in rabbit cardiomyocytes [40]. It was reported that despite a 5- to 6-fold increase in the amount of active CaMK, the contractility was unaltered because the CaMK-dependent RyR phosphorylation was increased and consequently SR $\mathrm{Ca}^{2+}$ leak was greatly augmented [40]. Our modelling implies that in the acute overexpression state the CaMKdependent the RyR leak might work as a compensatory mechanism to restore some features of E-C coupling by limiting the effects of overly enhanced CaMK activity on the calcium signals.

CaMK overexpression simulations also give predictions of how the altered calcium signalling affects the activity of other calcium-activated enzymes. For example, calcineurin activity, which is a master regulator of the expression of cardiac genes [41] and can promote cardiac hypertrophy and failure [8], is indirectly modulated by CaMK activity. The augmented calcium signals in CaMK3X* simulations increase the CaN activity by $69 \%$ and conversely the blunted calcium signals in CaMK3X simulations reduce the CaN activity by $90 \%$ at $1 \mathrm{~Hz}$ pacing compared to WT. Interestingly, when the normal pacing induced calcium changes are impaired in the CaMK3X model, the pacing induced increase in the CaN activity 

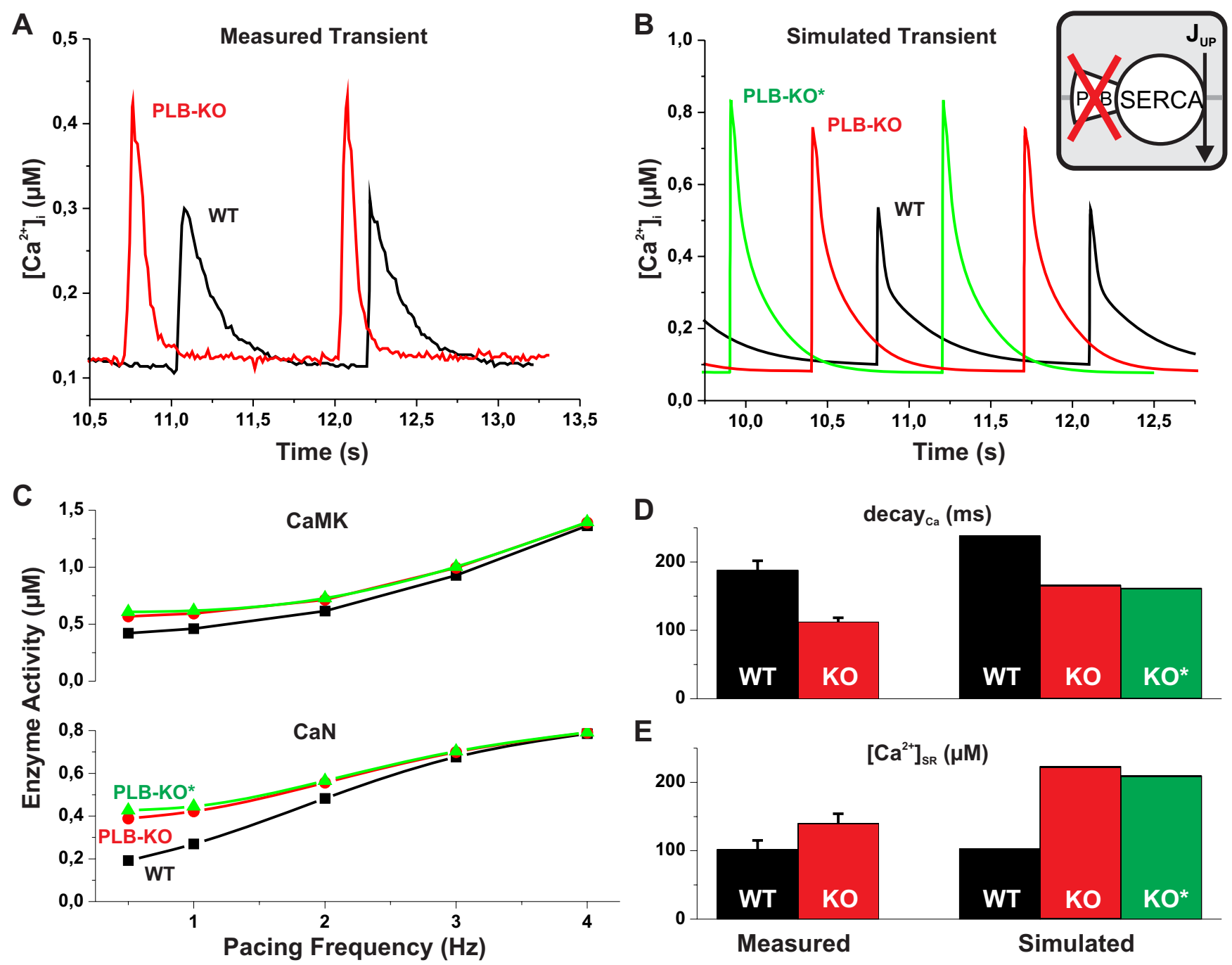

E

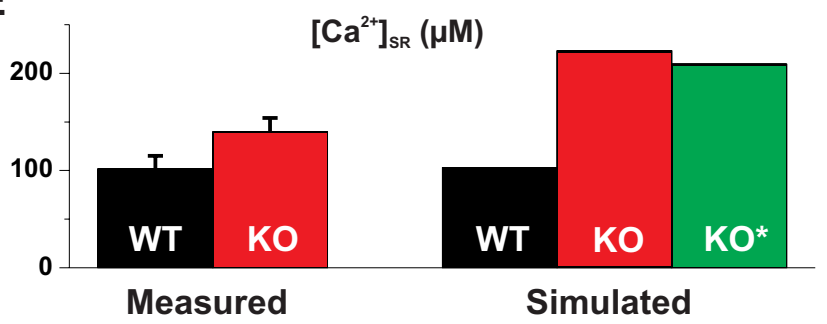

\section{Figure 5}

Comparison of experimental data and simulated results of WT and PLB knockout. Results of WT, PLB knockout and PLB knockout without compensation are shown with black, red and green symbols, respectively. (A) and (B) Two postrest $\mathrm{Ca}^{2+}$ transients from experimental [32] and simulated data are shown. There is a marked similarity of the shapes of the corresponding $\mathrm{Ca}^{2+}$ transients of the simulated results and the measurements, e.g., the amplitude ratio of PLB-KO vs. WT is I.6 in both the in vivo and the in silico experiments. The amplitude of the $\mathrm{Ca}^{2+}$ transient is a further $12 \%$ larger in the PLB-KO* test case (knockout with no compensations). (C) Amount of active CaMK and $\mathrm{CaN}$ as a function of pacing frequency. Compared to WT the mean activities of CaMK and $\mathrm{CaN}$ increase by $35 \%$ and $102 \%$ for PLB-KO, and by $44 \%$ and $122 \%$ for PLB-KO* at 0.5 $\mathrm{Hz}$ pacing. These deviations from behaviour of the WT myocyte are attenuated when the pacing frequency is increased. (D) Time constants of the $\left[\mathrm{Ca}^{2+}\right]_{i}$ transient decay. Measured data [19] is compared to simulated results at $0.5 \mathrm{~Hz}$. The value of is decreased by $26 \%$ and $28 \%$ compared to WT for the PLB-KO and PLB-KO* simulations, respectively, and by $40 \%$ in the experiments of Li et al. [19]. (E) SR Ca ${ }^{2+}$ content calculated from measured data [19] and simulated results at $0.5 \mathrm{~Hz}$. The increases of $\left[\mathrm{Ca}^{2+}\right]_{S R}$ appears to be exaggerated in silico. However, an earlier report by Chu et al. [33] showed an $86 \%$ increase of $\left[\mathrm{Ca}^{2+}\right]_{S R}$ in the PLB-KO mouse myocytes compared to WT. Thus, the model prediction of the SR calcium content is in good qualitative agreement with the experiments.

(from $0.5 \mathrm{~Hz}$ to $4 \mathrm{~Hz}$ ) is decreased by $32 \%$ (Figure $7 \mathrm{H}$ ). Consequently, the CaN activity is lower even at high pacing frequencies $(47 \%$ reduction at $4 \mathrm{~Hz}$ ) compared to WT. Another interesting observation is that the putative CaMK-induced RyR leak tends to normalize the CaN activity in the CaMK3X* test case, i.e. the pacing induced changes are more similar to $\mathrm{WT}$. This is again an example of a mechanism that could help a complex biological system maintain its physiological function in spite of genetic interventions. 

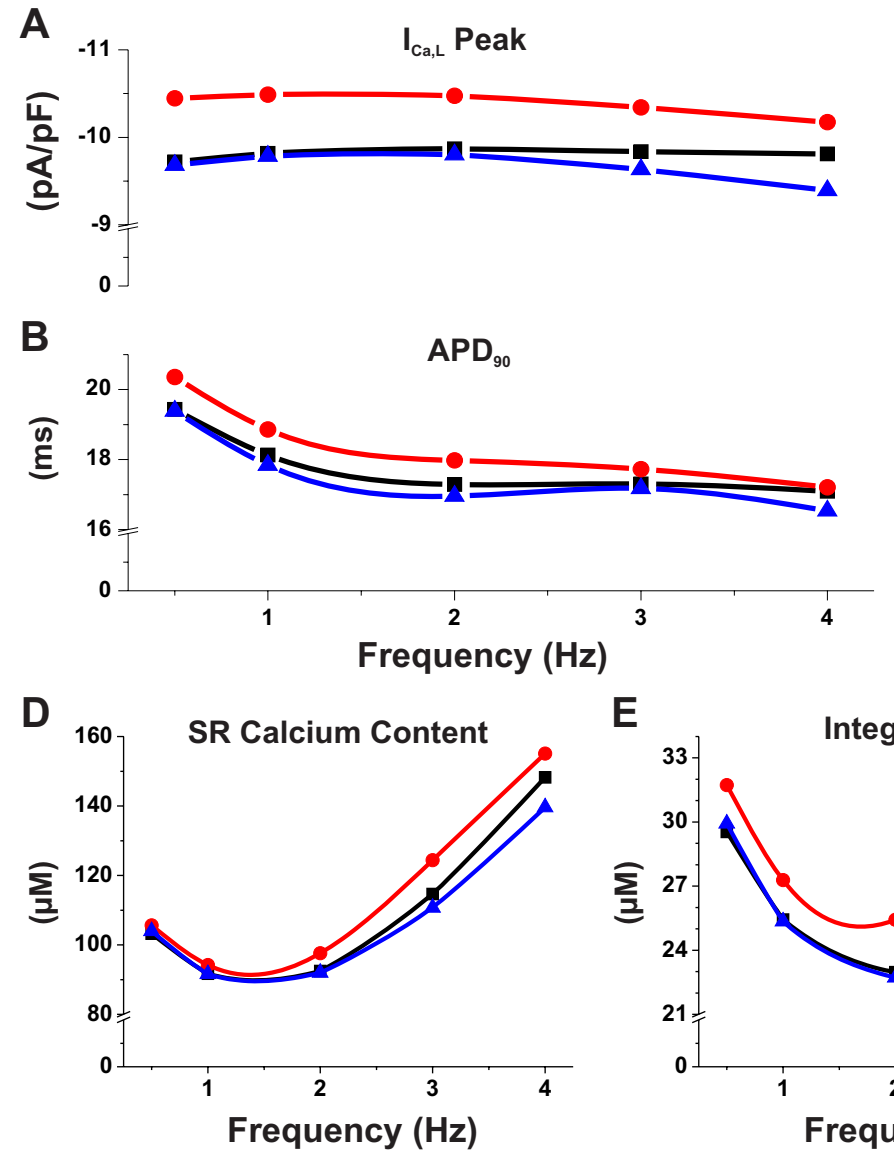

E

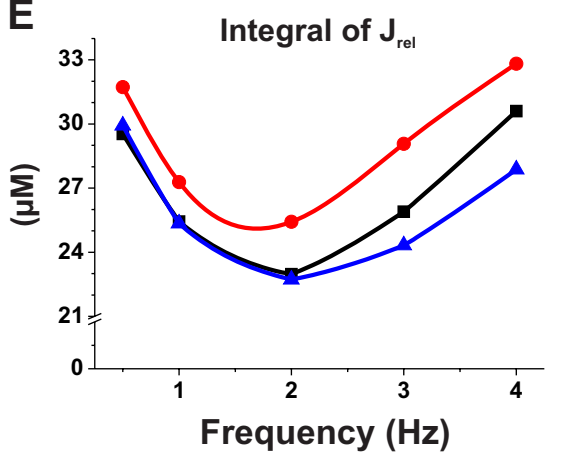

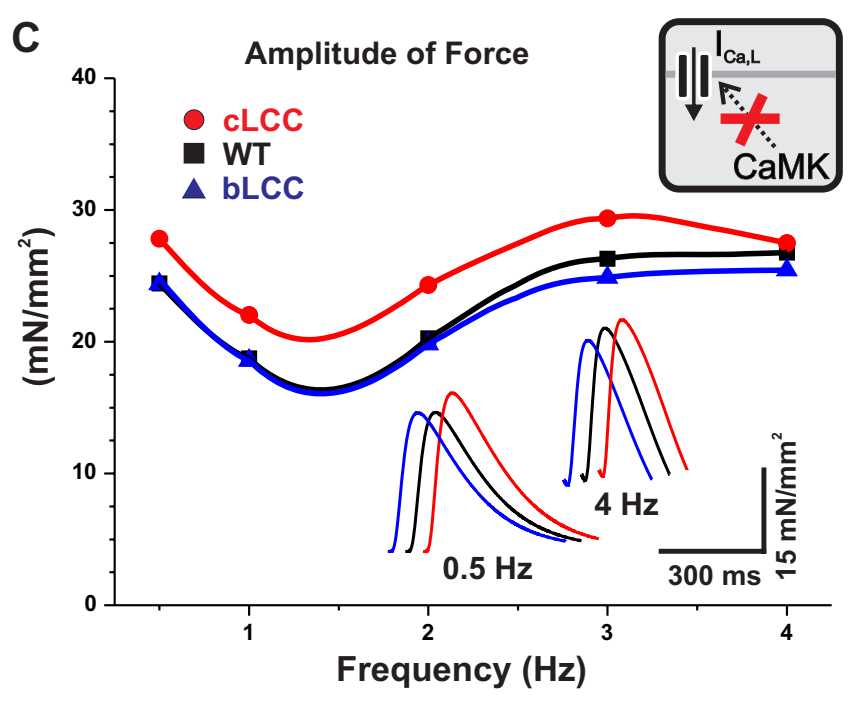

$\mathbf{F}$

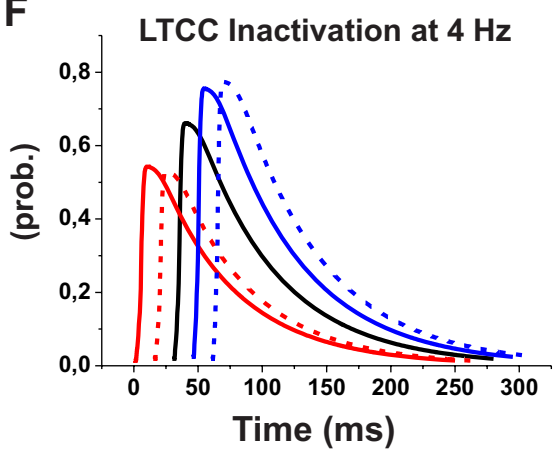

\section{Figure 6}

Comparison of WT and transgenic LCC models. The results of TG models with constitutively active CaMK-dependent phosphorylation (cLCC) and blocked phosphorylation (bLCC) of LCC are depicted with red circles and blue triangles, respectively. These are compared to simulation results of wild-type model (black squares). (A) Peak value of L-type calcium current $\left(\mathrm{I}_{\mathrm{Ca}, \mathrm{L}}\right)$ as a function of pacing frequency. The $\mathrm{I}_{\mathrm{C}, \mathrm{L}}$ peak amplitude of $\mathrm{bLCC}$ model deviates rather little from the WT $(-4.3 \%$ at $4 \mathrm{~Hz}$ ). In the $\mathrm{CLCC}$ model, the peak value of $\mathrm{I}_{\mathrm{Ca}, \mathrm{L}}$ is larger than in the WT (+7.5\% at $0.5 \mathrm{~Hz}$ pacing), but the deviation decreases as pacing frequency increases. (B) Action potential duration $\left(90 \%\right.$ recovery, $\left.A P D_{90}\right)$ presented as a function of pacing frequency. Compared to WT, the $A P D_{90}$ is virtually unchanged in both TG models. (C) Contraction force amplitude as a function of pacing frequency. The difference in the force amplitude is also very small: $-4.9 \%$ for bLCC (at $4 \mathrm{~Hz}$ ) and $+14 \%$ for cLCC (at $0.5 \mathrm{~Hz}$ ). Inset shows twitch force of the WT and TG model at $0.5 \mathrm{~Hz}$ and $4 \mathrm{~Hz}$ pacing frequencies. (D) and (E) SR $\mathrm{Ca}^{2+}$ content $\left(\left[\mathrm{Ca}^{2+}\right]_{\mathrm{SR}}\right)$ and the integral of $\mathrm{Ca}^{2+}$ release from the $\mathrm{SR}\left(\mathrm{J}_{\text {rel }}\right)$ during one AP plotted as a function of pacing frequency. There is very little change in the $\left[\mathrm{Ca}^{2+}\right]_{S R}$ at low pacing frequencies. The maximum deviation from WT is seen at $4 \mathrm{~Hz}$ pacing: $-6 \%$ and $+5 \%$ for bLCC and CLCC, respectively. The integral of $J_{\text {rel }}$ changes slightly more $-9 \%$ and $+7 \%$ for bLCC and cLCC, respectively. (F) Demonstration of the autoregulation involving $\mathrm{I}_{\mathrm{C}}, \mathrm{L}$ and $\mathrm{J}_{\mathrm{rel}}$. Dashed lines present acute transgenic situation, in which the LCC inactivation is calculated from the WT parameter values. Note that the time axis of the traces has been shifted for easier comparison.

\section{Discussion}

Our results highlight the intrinsic complexity of cardiomyocyte E-C-coupling, which originates from the interdependencies of regulatory mechanisms involving calcium and the components regulating the membrane excitability. Facing this complexity, experimental observations, even clever and ingenious ones, may not be enough to reveal the causal connection of the cellular signalling pathways, where networks operating in parallel form feed- back loops that control the dynamic physiological features of the cells. These complex networks give some fundamental and unanticipated properties to the cell function. For example, they make the system more robust, i.e., tolerant to change in the single part of a signalling network [42]. Even more challenging task is faced when the networks are interfered like in studies of genetically engineered models. When some cellular function is disrupted by genetic intervention, the resulting phenotype is not 
A

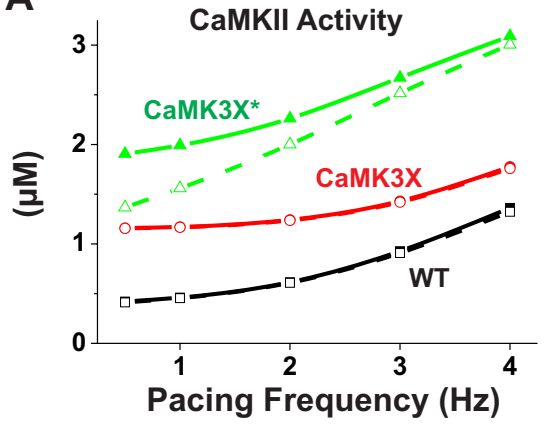

D

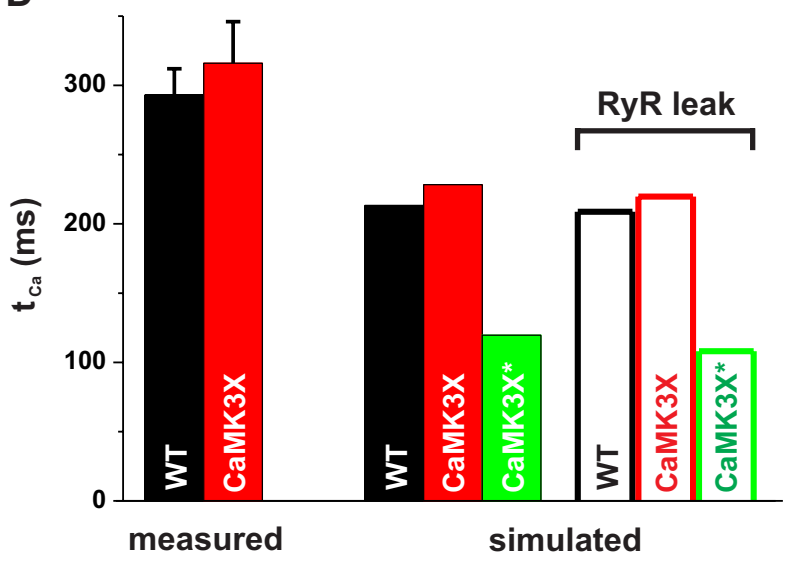

B C

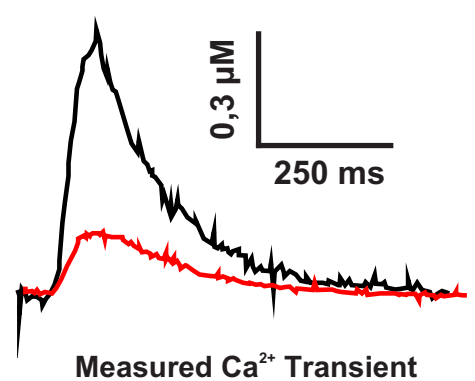

C

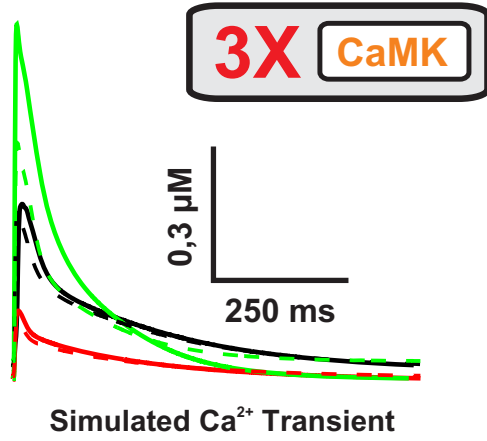

E

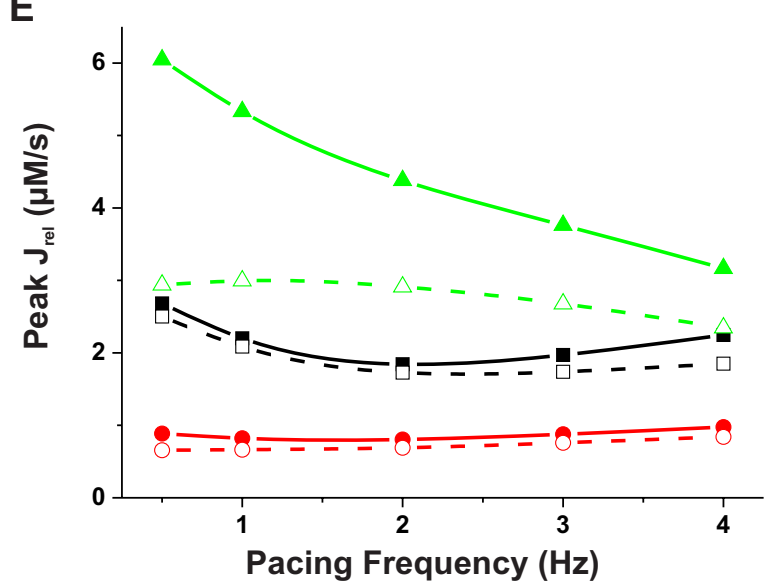

$\mathbf{F}$

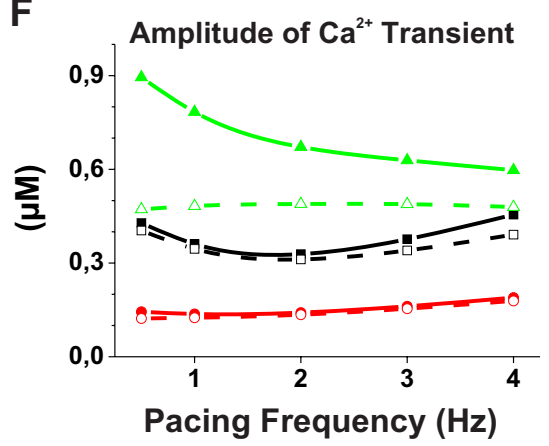

G

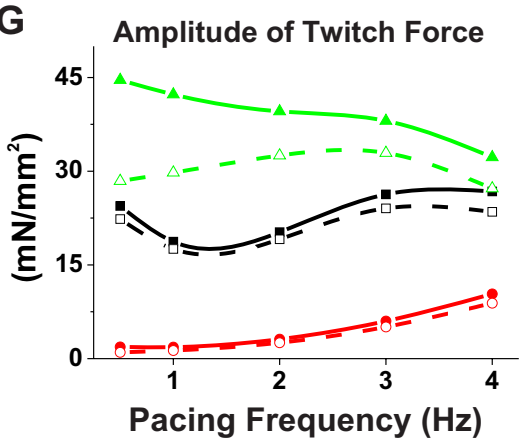

H

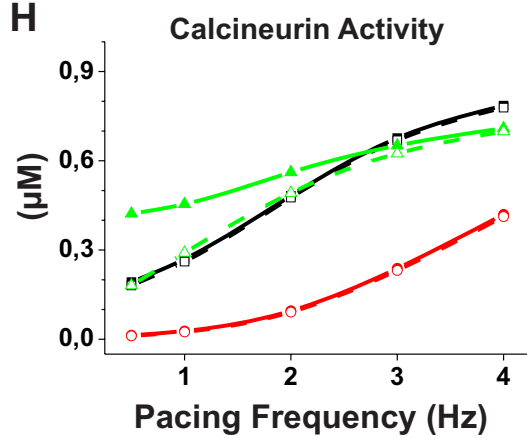

Figure 7

Comparison of experimental data and simulated results of WT and CaMK. Black (squares), red (circles) and green (triangles) symbols indicate WT, CaMK overexpression (CaMK3X) and CaMK overexpression with no compensations (CaMK3X*), respectively. The corresponding test cases without and with CaMK induced SR leak are depicted with closed symbols \& continuous lines and open symbols \& dashed lines. (A) CaMK activity as a function of pacing frequency. The pacinginduced $(0.5$ to $4 \mathrm{~Hz})$ increase of CaMK activity is $35 \%$ smaller for CaMK $3 X$ vs. WT. (B) and (C) $\left[\mathrm{Ca}^{\mathrm{r}+}\right]_{\mathrm{i}}$ transient at I Hz. Compared to WT, the amplitude of the measured [20] and the simulated transient changes by $-77 \%$ and $-62 \%$ due to CaMK overexpression, respectively, and CaMK $3 X^{*}$ by $+117 \%$. (D) Time constants of the $\left[\mathrm{Ca}^{2+}\right]_{\text {i }}$ transient decay. At I Hz, the combination of CaMK overexpression and compensational changes increases the time constant of measured [20] and simulated $\mathrm{Ca}^{2+}$ transient decay by $7.8 \%$ and $14 \%$, respectively. Whereas, the mere overexpression (CaMK3 $3 *$ ) decreases ca by $41 \%$ compared to WT. (E) Peak value of SR calcium release as function of pacing frequency. WT and CaMK3X were not affected to a large extent by the leakiness of RyR. Whereas, in the CaMK3X* test case, the behaviour changes strikingly. $(F)$ and $(G)$ The amplitudes of $\mathrm{Ca}^{2+}$ transient and contractile force as a function of pacing frequency. A "leaky" RyR tends to normalize the functionality of the CaMK3X* test case, but has little effect in WT and CaMK3X. (H) Activity of $\mathrm{CaN}$ as a function of pacing frequency. At I Hz pacing, CaN activity for CaMK3X is reduced to $10 \%$ of the WT value and increased by $69 \%$ for CaMK3X*. Increased pacing is unable restore $\mathrm{CaN}$ of CaMK3X to the WT level, whereas the deviation of CaMK3 $X^{*}$ from WT is reversed by faster pacing. Interestingly, the RyR leakiness brings the $\mathrm{CaN}$-frequency curve of $\mathrm{CaMK} 3 \mathrm{X}^{*}$ closer to WT. 
necessarily exactly what was expected. Instead, homeostatic regulatory mechanisms in cells tend to minimize the effects of the mutation on the phenotype.

The presented model is the first mathematical model of mouse ventricular myocyte E-C coupling that also includes the regulation of the calcium transport machinery through the activation of CaMK. The model has properties common to complex biological systems, which explain the basic features of cardiomyocyte function: 1) pacing-induced changes in calcium dynamics via CaMKdependent regulation, as well as 2) robustness against experimental interventions (caffeine-induced calcium release) and genetic modifications (PLBKO and disruption of CaMK-dependent modulation of LCC). The simulations with the model give fundamental information on interrelations between different signalling pathways in cardiomyocyte E-C coupling and clarify the role of parallel feedback loops in maintaining the operation of cardiomyocyte E-C coupling. We showed that through the feedback loops cardiomyocytes are surprisingly resistant to alterations in the activity of single endpoint components in the signalling networks, whereas interventions disrupting the feedback loops will compromise the function. According to our simulations, these inherited properties of cardiomyocyte E-C coupling are likely to define the impact of genetic manipulations on the end-phenotype of the cardiomyocytes.

\section{Limitations of the Study}

The fundamental challenge in developing an E-C coupling model is the rather large variability of experimental data. Therefore, it would be an irrelevant and futile effort to try to fit the behaviour of the model perfectly to one single set of in vivo data. Instead, it is more essential that the outputs of the model agree qualitatively with the majority of the measured results, as is the case with the three fundamental outputs (AP, $\mathrm{Ca}^{2+}$ transient and force) in our model. Furthermore, the model was also able to simulate faithfully such multivariable cellular phenomena as the force-frequency relationships and the caffeine pulse experiments. This kind of high-level validation is crucial for a model that is comprised of multitude of submodels, because for most of the model parameters there is no corresponding measurement data, to which the parameter values could be directly fitted; a second fundamental challenge in this modelling field.

The isoform-specific differences of the CaMK reaction chain in the neuronal vs. cardiac tissue warrant further studies. However, a fair assumption, one that we have made, is that these isoforms of the kinase behave in a rather similar manner, since they share 89-93\% sequence similarity in their catalytic and autoregulatory domains [43]. This issue was recently studied by Chiba et al. with a mathematical model that included the CaMK-CaM interaction dynamics specific to neurons and cardiomyocytes [44]. Our approach to describe this isoform divergence is, albeit non-mechanistic, a coherent one (see Methods section for details). The results of Chiba et al. [44] and Saucerman et al. [45] also underline the significant role of PP1 activity in CaMK dynamics. In addition to PP1, the enzyme reaction network of Bhalla and Iyengar [46] includes also the other two main phosphatases, CaN and PP2A, found in cardiac myocytes. Thus, it is a comprehensive description of enzyme kinetics with notable application potential in future studies as well.

Despite the limitations mentioned above, our model reproduces faithfully the main features E-C coupling of mouse ventricular myocytes. Simulation results also suggest that, despite or because of the complexity of the model, it behaves robustly enough to be a suitable and valid platform to study the physiological and pathophysiological phenomena in mouse cardiac myocytes. Especially interesting issue that can be targeted with our model is the role of CaMK in various heart failure conditions.

\section{Physiological Role of CaMK in Cardiomyocytes}

CaMK is a multifunctional holoenzyme that has modulates E-C coupling by phosphorylating SERCA, PLB, RyR and LCC $[14,40,47,48]$. CaMK goes through a process of autophosphorylation, i.e. the phosphorylated state continues even after the $\mathrm{Ca}^{2+} \mathrm{CaM}$ complex has been removed, which leads to prolonged activation of CaMK [49]. It has been shown that the enzyme can decode the frequency and the amplitude of $\mathrm{Ca}^{2+}$ spikes into distinct levels of kinase activity [16]. With this unique combination of features CaMK mediates the beating frequencydependent regulation in cardiac myocytes and establishes a feedback signalling network that controls cardiomyocyte $\mathrm{Ca}^{2+}$ signals and excitability. Apart from this physiological function, CaMK has been verified as a proarrhythmic signalling molecule and may therefore offer novel solutions for antiarrhythmic therapy $[35,50]$. In this study, we focused on the CaMK-dependent regulation of E-C coupling. The presented mathematical model was validated both in WT and transgenic test cases. Thus, it forms a good base for further studies of the role of CaMK, and CaN, e.g. in arrhythmia and excitation-transcription coupling.

\section{Phospholamban Knockout Model}

The phospholamban knockout model is one of the few reported mouse models, where genetic manipulation produces enhancement of the cardiac function instead of pathological developments and failure. In theory, the absence of PLB-dependent inhibition of SERCA should increase the SR calcium uptake, which would result in faster decay of calcium transients, elevated $\left[\mathrm{Ca}^{2+}\right]_{\mathrm{SR}}$ and a 
subsequent increases in the amplitudes of the calcium transients. The analysis of the PLB-KO mice showed that all of the expected changes were present in the PLB-KO cardiac myocytes and that the PLB ablation had induced only very mild phenotypical compensations $[19,33]$. In our model, the experimental results from the PLB-KO mouse were mostly reproduced by ablation of the PLB, and the reported compensatory reduction of the RyR expression did not significantly change the E-C coupling.

The enhanced systolic $\left[\mathrm{Ca}^{2+}\right]_{\mathrm{i}}$ also activates both of the calcium-dependent enzymes in the model. Because CaMK is predominantly activated at relatively high frequencies (Figure 4), increase of the amplitude of calcium transient at low frequencies elevates CaMK activity only modestly (35\% at $0.5 \mathrm{~Hz}$ ) compared to calcineurin activity, which is doubled at low frequency ( $102 \%$ increase at $0.5 \mathrm{~Hz}$ pacing). Since calcineurin regulates cardiac gene expression [41] and promotes cardiac hypertrophy and even failure [8], enhanced calcineurin activity should have a great impact on the cardiac phenotype. However, according to the simulations presented here, at higher frequencies both the CaMK and CaN activities of PLB-KO myocytes are normalized. At $4 \mathrm{~Hz}$, the enzyme activities of PLB-KO and WT myocytes are identical, suggesting that at normal mouse heart rates $(5-10 \mathrm{~Hz})$ CaMK and $\mathrm{CaN}$ are not changed in PLB-KO hearts.

From the physiological point of view, ablation of PLB causes the myocyte to recruit more calcium-activated force than would be required at low pacing frequencies. This change alone increases the energy consumption of the myocyte, since the contractile element and SERCA are the main energy consuming components of the system. Therefore it is a surprise that the cardiac phenotype of the PLB-KO mouse is so close to the WT and without pathological changes; a finding that has been shown to endure even in the long-term [51].

\section{Transgenic Model of CaMK-Dependent Regulation of L- type Calcium Channel}

Considering the fundamental role that $\mathrm{I}_{\mathrm{Ca}_{2} \mathrm{~L}}$ has in $\mathrm{E}-\mathrm{C}$ coupling as the initiator of the CICR process, the enzymatic regulation of LCCs is an extremely interesting subject for in silico studies. The CaMK-dependent facilitation of $\mathrm{I}_{\mathrm{Ca}, \mathrm{L}}$ is considered to be an important part of the physiological regulation of E-C coupling (for review see [52]) but it may also be involved in arrhythmias [36].

Despite the crucial role of $\mathrm{I}_{\mathrm{Ca} \text {, }}$, its CaMK-dependent regulation appears to be less essential for the regulation of $\mathrm{E}$ $\mathrm{C}$ coupling in mouse ventricular myocytes. In both cases, bLCC and CLCC, with disrupted CaMK-dependent modulation the autoregulatory link between $\mathrm{I}_{\mathrm{Ca}, \mathrm{L}}$ and $\mathrm{J}_{\text {rel }}$ tends to reduce the original effect of altered $\mathrm{I}_{\mathrm{Ca}} \mathrm{L}^{\prime}$ thus bringing the TG system closer to WT behaviour. This is a good example of how difficult it is to combine a holistic point of view based on the data from experimental findings. For example, it has been reported that the super-maximal change of $\mathrm{I}_{\mathrm{Ca}, \mathrm{L}}$ induced by the 5-6 fold overexpression of CaMK is $22 \%$ of the calcium current [40]. If we accept that this effect is significantly higher than the modulation induced by maximally activated endogenous CaMK, which would occur at the highest cardiomyocyte beating rates (mouse $\sim 10 \mathrm{~Hz}$ ), then the CaMK-induced modulation of $\mathrm{I}_{\mathrm{Ca}, \mathrm{L}}$ at pacing rates applicable to isolated mouse cardiomyocytes $(0.5-2 \mathrm{~Hz})$ would be minute. In addition, in experiments all other normal cellular feedback systems controlling $\mathrm{I}_{\mathrm{Ca}, \mathrm{L}}$ will be excluded, which further biases evaluation of the potential impact of the CaMK modulation on the $\mathrm{I}_{\mathrm{Ca}} \mathrm{L}$ and especially on the function of the whole cell. This was well demonstrated by the model, where the large CaMK facilitation could be expected to produce a large modification of E-C coupling, but in silico the effect turned out to be rather small.

\section{CaMK Overexpression Model}

To study the possible role of CaMK activity in the development of hypertrophy and failure, a mouse model overexpressing cytosolic CaMK was generated by Maier et al. [20]. This genetic intervention results in unique changes in cardiomyocyte calcium signalling, cardiac hypertrophy and dilated heart failure [20], suggesting that chronic CaMK overexpression triggers drastic alteration in cardiomyocyte gene expression.

In our model, an increase in the amount of CaMK has dramatic effects on myocyte function through an increase in the CaMK activity and subsequent activation of CaMK targets. This leads to greatly augmented calcium release and uptake resulting in enhanced calcium signals. These are quite the opposite to the reported phenotype of the CaMK overexpression mouse, suggesting that the compensatory changes in the gene expression have more impact on the CaMK-TG phenotype than the CaMK-dependent regulative mechanisms per se. Supporting this, when the protein expression changes of the CaMK-TG myocytes reported in [20] were incorporated into the model, our simulations produced blunted calcium signals, impaired force-frequency and calcium-frequency relations, just like in the experiments with CaMK-TG myocytes [20].

In order to understand the sequence of events leading to the endpoint phenotype, the acute effect of the genetic modification should be explored. Acute effects of CaMK were studied recently by adenoviral overexpression (5- to 6 -fold) of CaMK in isolated rabbit cardiomyocytes [40]. Surprisingly, CaMK overexpressing myocytes had normal calcium transient amplitudes and reduced SR calcium content [40]. To explain this it was suggested that the CaMK-induced RyR phosphorylation would increase the SR calcium leak, which in turn would reduce SR calcium 
load despite the CaMK-dependent increase in the SR calcium uptake $[20,40]$. In our simulations, the CaMKinduced RyR leak during CaMK overexpression (CaMK3X* test case) reduced the SR calcium content and release, in line with the experimental findings $[20,40]$. This leads to secondary effects: 1 ) due to smaller calcium transients compared to CaMK overexpression without the RyR leak, the amount of active CaMK and $\mathrm{CaN}$ are reduced and 2) the negative trend of the force-frequency relation is almost reversed. Thus, it would seem that in the acute phase of the overexpression state the CaMK-dependent RyR leak might be beneficial for the myocyte function, since it acts to limit the overly enhanced calcium signals. Due to the CaMK-induced RyR calcium leak, the initial change of the CaMK overexpression in the calcium signals is modest.

Why then does CaMK overexpression induce such extensive compensations at the level of transcription? CaMK overexpression differs fundamentally from PLB-KO in that it switches off the whole physiological feedback system between the cytosolic calcium signals and the CaMK. Therefore, it is likely that these sorts of manipulations, which destroy the ability of the cell to adapt to the functional demands, will trigger profound transcriptional compensations.

\section{Conclusion}

Mathematical modelling can be exploited as an integrative tool to dissect the underlying processes of cellular function in both physiological and pathophysiological situations. The potential of in silico studies lays in the ability to simultaneously observe multiple variables and to estimate such outputs that cannot be measured in the experiments. Our simulations show that modelling enables conclusions about the causalities between myocyte signalling cascades, which would be challenging to reach solely by interpretation and analysis of in vivo measurements. Thus, it is possible to gain more information of the 'autoregulatory' phenomenon in the cardiac myocyte. In the present study, we have demonstrated this for normal and three transgenic cell types.

\section{Methods}

We base our model of ventricular myocytes of adult mouse on three existing model components: 1) a model of cardiomyocyte electrophysiology by Bondarenko et al. $[53], 2)$ a description of the contractile element by Cortassa et al. [54] and 3) a biochemical scheme of CaMK activation by Bhalla and Iyengar [46]. A schematic drawing of the developed model is presented in Figure 1.

The model parameters were adjusted, whenever possible, according to experimental data (as specified in Tables 1, 2, $3 \& 4[55-75]$ or in the following sub-chapters) that was either retrieved directly from literature as numerical values or digitized from visualised data. The parameter values were estimated by direct adapting from literature (e.g., the $\mathrm{K}_{\mathrm{m}}$ value of SERCA) or indirect fitting (e.g., for maximum pump rate of SERCA based on the decay of $\mathrm{Ca}^{2+}$ transient); see Table 3 for a complete list of modified parameters. In either case, the fit was considered satisfactory when the values and the curves of the fits were within the standard error of the mean of the experimental values; see Table 2. In line with most common experimental settings, the model is nominally adjusted for a room temperature of $25^{\circ} \mathrm{C}$.

\section{Model of Cardiomyocyte Electrophysiology}

Due to the employment of a non-conservative stimulus current, the original mouse cardiomyocyte model by Bondarenko et al. [53] had serious stability issues that manifested as a chronic fluctuation of intracellular $\left[\mathrm{K}^{+}\right]$ and $\left[\mathrm{Na}^{+}\right]$; see Figure 8A. To increase the pacing steady state stability of the model, we implemented a conservative stimulation scheme, in which the stimulus current is carried by $\mathrm{K}^{+}$ions as suggested by Hund et al. [76]. This approach assured that the simulation results could indeed be obtained at a pacing steady state.

We have also made some modifications to the features and parameters of the Bondarenko model to obtain a better fit to the physiological data of mouse myocytes. A comprehensive improvement was the adjustment of calcium removal fractions of SERCA, NCX and plasma membrane $\mathrm{Ca}^{2+}$ ATPase (PMCA). The original set of parameters caused an imbalance between NCX and PMCA; see Figure $8 \mathrm{~B}$ and Table 2 . The modifications are described in detail in the following subchapters; see also Table 3.

\section{CaMK Reaction Scheme}

The CaMK part of the model is based on a previously published reaction scheme [46]. Information on the detailed structure of the reaction pathways, parameter values and computer source codes are available in the DOCQS Database [77]. The model of the CaMK reaction chain was originally designed for neurons, but its applicability for cardiac myocytes has already been documented in our previous studies [41]. Original values were used for reaction rate constants, but initial concentrations of some variables have been adjusted to the physiology of cardiac myocytes (see Table 4 for details). Essentially, the CaMK reaction scheme published by Bhalla et al. [46] is a highly detailed mathematical description (45 differential equations) based on extensive biochemical studies, thus, it offers novel possibilities for studying the regulation of E$\mathrm{C}$ coupling in a way not possible for example with the simplified (one differential equation) scheme introduced by Hund et al. [78]. A good example of this potential is the overexpression of CaMK that is investigated in this paper. 
Table 3: Modified parameter values of the previously published model components

\begin{tabular}{|c|c|c|c|}
\hline Symbol & Description & Criteria for Modification & Value \\
\hline$G_{\mathrm{Na}}$ & Maximum conductance of fast $\mathrm{Na}^{+}$current $(\mathrm{mS} / \mu \mathrm{F})$ & Increasing $\mathrm{dV} / \mathrm{dt}_{\max }$ of $\mathrm{V}_{\mathrm{m}}$ & 14.5 \\
\hline$I_{P M C A}^{\text {IIIAx }}$ & Maximum $\mathrm{Ca}^{2+}$ transport rate of $\mathrm{PMCA}(\mathrm{pA} / \mathrm{pF})$ & Adjusting $\mathrm{Ca}^{2+}$ circulation fraction & 0.05 \\
\hline$G_{C a b}$ & Conductance of background $\mathrm{Ca}^{2+}$ current $(\mathrm{mS} / \mu \mathrm{F})$ & Adjusting SR calcium content & $3.4 \times 10^{-4}$ \\
\hline$I_{N K A}^{\text {IntaA }}$ & Maximum conductance of NKA $(\mathrm{pA} / \mathrm{pF})$ & Matching to recent data of ref. [67] & 1.4 \\
\hline$K_{m, N a i}$ & Half maximal $\left[\mathrm{Na}^{+}\right]_{\mathrm{i}}$ sensitive activation $(\mathrm{mM})$ & (same as above) & 18.6 \\
\hline$n_{\text {NKA }}$ & Exponent of NKA Hill equation & (same as above) & 3.2 \\
\hline$k_{\text {htrpn }}^{+}$ & $\mathrm{Ca}^{2+}$ on-rate for troponin high-affinity sites $\left(\mu \mathrm{M}^{-1} \mathrm{~ms}^{-1}\right)$ & Adapted from ref. [8I] & $2.37 \times 10^{-3}$ \\
\hline$k_{\text {htrpn }}^{\text {tupn }}$ & $\mathrm{Ca}^{2+}$ off-rate for troponin high-affinity sites $\left(\mathrm{ms}^{-1}\right)$ & (same as above) & $3.2 \times 10^{-5}$ \\
\hline$k_{\text {ltrpn }}^{\text {inpn }}$ & $\mathrm{Ca}^{2+}$ on-rate for troponin low-affinity sites $\left(\mu \mathrm{M}^{-1} \mathrm{~ms}^{-1}\right)$ & $\begin{array}{l}\text { Lowering of the baseline tension according } \\
\text { to data of }[21,22]\end{array}$ & 0.07 \\
\hline$S L$ & Sarcomere length $(\mu \mathrm{m})$ & Adapted from ref. [22] & 2.0 \\
\hline$f$ & Scaling factor for the speed of contraction generation'(see eq. All I in ref.) & $\begin{array}{l}\text { Matching the force transient to data of } \\
\text { refs. }[21,22]\end{array}$ & 2.3 \\
\hline$f_{1 / 2}^{u p n}$ & $\begin{array}{l}\text { Scaling factor for the half maximal transition rate of tropomyosin from } \\
\text { permissive to nonpermissive (see eq. AlI } 2 \text { and AlI } 3 \text { in ref.) }\end{array}$ & (same as above) & 2.8 \\
\hline
\end{tabular}

In Figure 1, the CaMK submodel is presented as a simplified control diagram. A rise in the $\left[\mathrm{Ca}^{2+}\right]_{\mathrm{i}}$ level increases $\mathrm{Ca}^{2+}$ binding to $\mathrm{CaM}$, which in turn phosphorylates more CaMK and CaN. Phosphorylation of the latter induces phosphorylation of protein phosphatase 1 (PP1). The autophosphorylation of CaMK is presented as a positive feedback loop and PP1 inhibition as negative feedback. The input for the enzyme reactions is $\left[\mathrm{Ca}^{2+}\right]_{i}$ upscaled by a factor of two. This is a non-mechanistic approach; however, it emulates the higher sensitivity of cardiac vs. neuronal CaMK isoform to $\left[\mathrm{Ca}^{2+}\right]$, which was studied in detail by Chiba et al. in their recent work [44]. They reported that the calcium concentration value of half-maximal activation of CaMK autophosphorylation is $\sim 2.5 \mu \mathrm{M}$ and $\sim 1.2$ $\mu \mathrm{M}$ for the neuronal and cardiac isoform, respectively. Thus, the scaling factor of two matches well to the findings. It is also in line with the assumption that CaMK is located in such calcium signalling sub-domains, in which calcium concentration reaches, on average, higher peak values than in the bulk cytosolic compartment.
The regulatory effect that CaMK has on SERCA, PLB, LCC and RyR is calculated from the level of active CaMK in the cytosol with the following equation

$$
C a M K_{\text {reg }}=\frac{C a M K_{\text {active }}^{n}}{K_{m, C a M K}^{n}+\mathrm{CaMK} K_{\text {active }}^{n}},
$$

where the half maximal CaMK activity, $K_{m, \text { CaMK }}=1.2 \mu \mathrm{M}$ and $n=3$. We tested a variety of values for these two parameters and the best fit to experimental data of the frequency-dependence of the intracellular calcium dynamics (see Figure 2B), and FDAR (see Table 2) was obtained with these values.

The effect of CaMK-dependent regulation of calcium transport mechanisms is demonstrated in Figure 8C. The two sets of traces refer to simulations run with either a normal model scheme (wild-type; black) or a scheme, in which the CaMK activity has been "clamped" to the quies-

Table 4: Initial conditions for the differential parameters

\begin{tabular}{|c|c|c|c|}
\hline Parameter & Description & Value $(\mu \mathrm{M})$ & Refs. \\
\hline $\mathrm{CaM}$ & Calmodulin & 6 & {$[75]$} \\
\hline CaMK & Basal activity of $\mathrm{Ca}^{2+} / \mathrm{Calmodulin-dependent} \mathrm{Kinase}$ & $10^{*}$ & [17] \\
\hline total_CaMK & Total amount of $\mathrm{Ca}^{2+} / \mathrm{Calmodulin-dependent} \mathrm{Kinase} \mathrm{(buffered)}$ & $10^{*}$ & {$[17]$} \\
\hline CaNAB_Ca2 & Calcineurin with two $\mathrm{Ca}^{2+}$-sites occupied & I & [46] \\
\hline II & Unphosphorylated form of Protein Phosphatase Inhibitor-I & 1.8 & [46] \\
\hline II_x & Phosphorylated form of Protein Phosphatase Inhibitor-I & 0.001 & {$[46]$} \\
\hline PPI_active & Phosphorylated form of Protein Phosphatase I & 1.8 & [46] \\
\hline tot_PPI & Total concentration of Protein Phosphatase 2A & 1.8 & {$[17]$} \\
\hline PP2A & Phosphorylated form of Protein Phosphatase 2A & 0.12 & {$[46]$} \\
\hline PKA_active & Phosphorylated form of Protein Kinase A (buffered) & 0.014735 & {$[17]$} \\
\hline--- & Parameters of the action potential model. & --- & [53] \\
\hline--- & Parameters of the contraction model. & --- & {$[54]$} \\
\hline
\end{tabular}

* A simplified approach to represent the 10 subunits, when CaMK concentration is I $\mu$ M. 

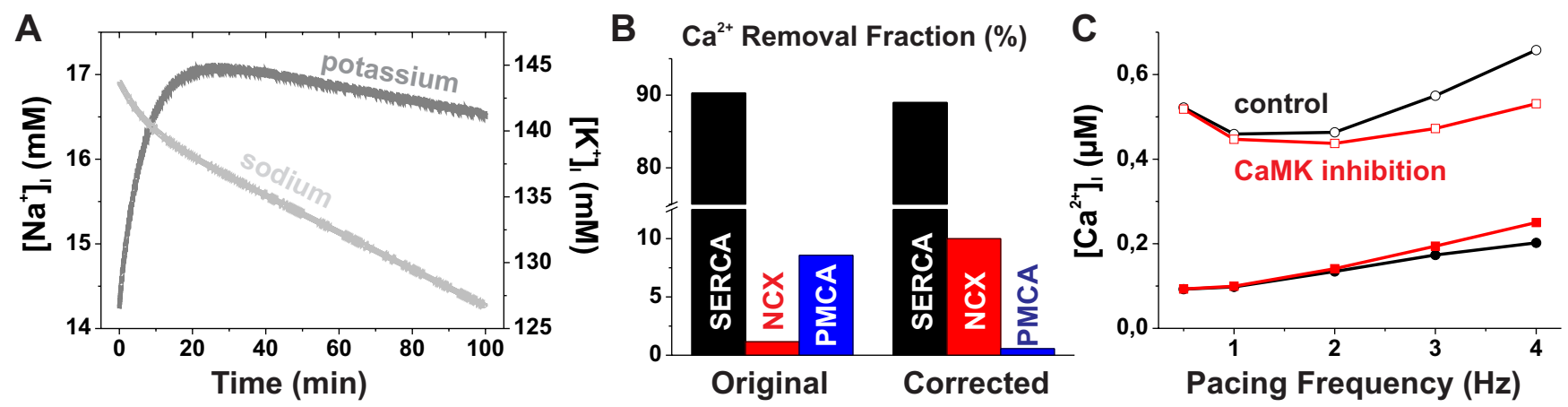

Figure 8

Stability of the model and characteristics of the CaMK-dependent calcium dynamics. (A) Intracellular $\mathrm{Na}^{+}$and $\mathrm{K}^{+}$ concentrations drift during a normal pacing stimulation at I Hz with the original Bondarenko model [53] and the model actually never stabilizes to physiological steady-state. Table I shows the corresponding values obtained with the developed model. (B) In the original Bondarenko model the removal fractions of NCX and PMCA were distorted reversely; see also Table 2. (C) Inclusion of the CaMK-dependent regulation of the calcium transport mechanisms enhances the positive dependence of systolic calcium (open symbols) on the pacing frequency. It also limits the excess rise of diastolic calcium (closed symbols) with high pacing frequencies, in line with the experimental findings (see Figure $2 \mathrm{~B}$ ).

cent level (CaMK inhibition; red). As the comparison with Figure 2B demonstrates, inclusion of the CaMK-dependent regulation of the calcium transport mechanisms is essential for the positive dependence of calcium transient amplitude on the pacing frequency. The regulation also limits the excess rise of diastolic calcium.

\section{Sarcoplasmic Reticulum $\mathrm{Ca}^{2+}$ ATPase}

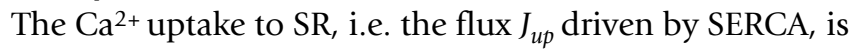
described with an equation that was originally formulated by Jafri et al. [79]. In our model, we modified that equation by using the same principles that Hund et al. used in their model of canine myocytes [78]. Parameters defining the direct CaMK modulation of SERCA as well as the indirect modulation via PLB are included in the equation

$$
J_{u p}=\left(\Delta J_{u p}^{\max } \cdot C a M K_{r e g}+1\right) \cdot V_{\max } \cdot \frac{\left[\mathrm{Ca}^{2+}\right]_{i}^{n}}{\left[\mathrm{Ca}^{2+}\right]_{i}^{n}+\left(K_{m, u p}-\Delta K_{m, P L B}^{\max } \cdot C a M K_{r e g}\right)^{n}} .
$$

The maximal relative change in the uptake rate that CaMK can induce, $\Delta J_{u p}^{\max }$, was set to $70 \%$ according to the experimental findings of Toyofuku et al. [47]. Whether CaMK increases $\mathrm{Ca}^{2+}$ uptake by SERCA or not has been a controversial issue according experimental findings. Both an increase [47] and a null-effect [80] have been reported. However, more recent in vivo experimental results support the positive effect of CaMK. Phosphorylation of PLB by CaMK relieves its inhibitory effect on SERCA. After testing a variety of values, we set the maximal change in the $K_{m}$,
${ }_{P L B}$ value to $0.17 \mu \mathrm{M}$, which is consistent with the experimental results of Odermatt et al. [80].

In addition to implementation of the CaMK dependence, we also decreased the value of $V_{\max }$ to $0.16 \mu \mathrm{M} / \mathrm{ms}$. This was done to increase the decay time constant of the $\mathrm{Ca}^{2+}$ transient, to correct the $\mathrm{Ca}^{2+}$ recirculation fractions of SERCA, NCX and PMCA, and to lower the SR $\mathrm{Ca}^{2+}$ content to a more physiological level (Table 2). Based on a wideranging iteration of the apparent $K_{m}$ value of SERCA, we decreased $K_{m \text {, up }}$ to $0.33 \mu \mathrm{M}$ and the exponent $n$ to 1.8 . These values gave the best overall fit to experimental data available on SERCA and they also corresponded well to the values suggested for all species [81]. The $K_{m, u p}$ value is somewhat higher than the values $0.23 \pm 0.04 \mu \mathrm{M}$ and 0.20 $\pm 0.04 \mu \mathrm{M}$ measured from mouse myocytes by Frank et al. [29], but this difference is reduced by CaMK regulation.

\section{L-Type Calcium Channel}

Dzhura et al. have shown that in single channel measurements CaMK promotes longer openings of LCC, i.e. gating mode 2 [14]. At whole cell level, this is seen as slowed inactivation [82]. Thus, in a deterministic modelling setting the latter mechanisms is a feasible way to represent the CaMK-dependent modulation. Based on experimental results we made the $\gamma$ parameter in the Markov model (see Figure 4 in ref. [53]) dependent on CaMK regulation according to equation (4). Parameter $K_{p c, \max }$ defines the maximum time constant for $\mathrm{Ca}^{2+}$-induced inactivation and $K_{p c \text {, half }}$ the corresponding half-saturation level. The CaMK modulation of parameter thus slows down the inactivation of LCC. 


$$
\gamma=\left(1.01-0.61 \cdot C a M K_{r e g}\right) \cdot K_{p c, \max } \cdot \frac{\left[\mathrm{Ca}^{2+}\right]_{s s}}{K_{p c, h a l f}+\left[C a^{2+}\right]_{s S}}
$$

Some experiments indicate that $I_{C a, L}$ can be increased by CaMK modulation as much as $40 \%$ to $50 \%$ [83,84]. However, in light of the most recent experimental results, the modulatory effect may be smaller. Gao et al. reported that the widely used CaMK inhibitor KN-93 has a CaMK-independent inhibitory effect on LCC [85]. They found that the inhibitory effect of a specific inhibitory peptide was less than one third of the inhibitory effect that KN-93 had on LCC [85]. Peptide inhibition studies done with rabbit cardiac myocytes acutely overexpressing CaMK also indicate a lesser modulatory increase of about 22\% [40]. Based on these experimental data, we set the modulation of parameter so that the maximal CaMK-dependent increase in $I_{C a, L}$ amplitude is $\sim 10 \%$.

\section{Ryanodine Receptor Calcium Channel}

Until recently, the effect of CaMK regulation on RyR (i.e. $\mathrm{Ca}^{2+}$ release from the $\mathrm{SR}$ ) has been a controversial issue. While some studies have shown that CaMK decreases $J_{\text {rel }}$ [86], other studies have reported the opposite result [20]. More recent experimental results [40] and modelling analysis [62], however, strongly support the latter hypothesis. Studies with RyRs incorporated into planar lipid bilayers suggest that CaMK phosphorylation of RyR increases the sensitivity of release to $\mathrm{Ca}^{2+}$ and thus increases RyR open probability [63]. We implemented CaMK modulation of the RyR in an analogous way to LCC. That is, we made parameter $k_{b}^{+}$, which defines the $\mathrm{Ca}^{2+}$ dependent transition rate from open state 1 to open state 2 (see Figure 1 in the original publication of Keizer et al. [64]), CaMK-dependent as described by the below equation.

$$
k_{b}^{+}=\left(9.18 \cdot C a M K_{\text {reg }}+0.82\right) \cdot 0.00405
$$

This mechanism increases RyR open probability as a function of increasing CaMK activity. The maximal CaMKdependent increase of $J_{\text {rel }}$ was set to $~ 10 \%$.

\section{The Transgenic Myocyte Models}

In this study, we evaluate three transgenic models: 1) the PLB knockout, 2) the disrupted CaMK-dependent modulation of LCC, and 3) the model of three-time overexpression of CaMK. To carry out the first test case we implemented two versions of the model according to the work by Li et al. [19]. Both of them lack the PLB inhibition of SERCA, i.e. we set value of parameter CaMK_reg to 1 in the denominator of equation (3). In addition to this, the first version also has a reduced RyR expression level (by $25 \%$ ) as reported by Chu et al. [33]. The second version describes a theoretical situation, where there are no such compensations. We refer to these two model versions in the text as "PLB-KO" and "PLB-KO*", respectively.

The two versions of the second test case were implemented by setting the value of parameter CaMK_reg in equation (4) either to 0 or 1 . That is, the first version of this model refers to a knock-out of CaMK-dependent phosphorylation of LCC and the second version to a constitutively active CaMK phosphorylation of LCC. These transgenic models have not been studied experimentally; instead they have been formulated according to the work of Grueter et al. [65] and Wu et al. [87], respectively. We refer to these two model versions in the text as "bLCC" and "cLCC", respectively. For the study of auto-regulatory link between LCC and RyR, we also estimated how the Ltype calcium current changes in an acute disruption of the CaMK-dependent regulation of LCC. That is, we calculated what the $\mathrm{I}_{\mathrm{Ca}, \mathrm{L}}$ would be if everything else remained normal. These simulations thus correspond to "WT clamp" protocol that cannot be reproduced in vivo.

The third test case demonstrates the effects of threefold overexpression of CaMK corresponding to the transgenic mouse model of heart failure developed by Maier et al. [20]. We implemented the overexpression by increasing the total values of CaMK concentrations from $10 \mu \mathrm{M}$ to 30 $\mu \mathrm{M}$ (see Table 4 for details). Furthermore, we made a second model version of this test case that includes also the compensatory changes reported by Maier et al. [20]. That is, we changed the expression levels of SERCA, RyR and NCX to $68 \%, 42 \%$ and $210 \%$, respectively, compared to WT, and we also reduced the SERCA/PLB ratio by $17 \%$ [20]. These two model versions are referred in the text as "CaMK3X*" and "CaMK3X", respectively. Additionally, we implemented parallel versions of the three test cases that include the putative CaMK induced diastolic SR leak according to the following equation:

$$
J_{\text {leak }}=\left(100 \cdot \mathrm{CaMK}_{\text {reg }}+1\right) \cdot 0.0025 \cdot\left(\left[\mathrm{Ca}^{2+}\right]_{J S R}-\left[\mathrm{Ca}^{2+}\right]_{S S}\right)
$$

This description of the leak sets, for example in the CaMK3X test case, about half a percent of the RyR channels to a constantly open state during diastole at $1 \mathrm{~Hz}$ pacing.

\section{Simulation Protocols}

The presented mathematical model is a set of 91 ordinary differential equations (ODEs). It was implemented to the Matlab $^{\mathrm{TM}}$ environment of technical programming. Simula- 
tion results were obtained by numerically integrating the model equations with a stiff ODE solver method (ode15s). Unless stated otherwise, all the presented results are steady state results that were obtained by letting simulations run as long as was needed for the model to reach a pacing steady state. The normal stimulus that we used was a current pulse (amplitude $-80 \mathrm{pA} / \mathrm{pF}$ and length $0.5 \mathrm{~ms}$ ) that was repeated according to the pacing frequency.

The caffeine pulse experiment was executed in silico by setting SERCA closed and RyR constantly open. The open probability was set to 0.25 instead of 1 to reflect the fact that in experiments the application of caffeine does not result in simultaneous and infinitely fast opening of RyR channels. The $\mathrm{Ca}^{2+}$ released from the SR is thus extruded from the cell mainly by NCX and secondly by PMCA (see Figure 2E).

\section{Sodium-Calcium Exchanger}

The description of the NCX current $\left(I_{N C X}\right)$ in the Bondarenko model [53] is based on a combined chemical reaction and free-energy barrier model developed by Luo and Rudy [55].

$$
\begin{aligned}
I_{N C X}= & k_{N C X} \times \frac{\left[\mathrm{Na}^{+}\right]_{0}^{3}}{K_{m, N a}^{3}\left[\mathrm{Na}^{+}\right]_{0}^{3}} \times \frac{\left[\mathrm{Ca}^{2+}\right]_{0}}{K_{m, \mathrm{Ca}}+\left[\mathrm{Ca}^{2+}\right]_{0}} \\
& \frac{\frac{\left[\mathrm{Na}^{+}\right]_{i}^{3}}{\left[\mathrm{Na} a^{+}\right]_{0}^{3}} e^{\eta V F / R T}-\frac{\left.f_{\mathrm{NCX}[\mathrm{Ca}}^{2+}\right]_{i}}{\left[\mathrm{Ca}^{2+}\right]_{0}} e^{(\eta-1) V F / R T}}{1+k_{s a t} e^{(\eta-1) V F / R T}}
\end{aligned}
$$

Bondarenko et al. used the cytosolic $\left[\mathrm{Ca}^{2+}\right]_{\mathrm{i}}$ value in the fourth term of the equation. However, we modified the equation according to previous models $[56,78]$, i.e., we upscaled the $\left[\mathrm{Ca}^{2+}\right]_{\mathrm{i}}$ with a constant $f_{\mathrm{NCX}}$. This simulates the higher sub-sarcolemmal $\left[\mathrm{Ca}^{2+}\right]$. After iteration, we obtained the best physiological fit when the $f_{\mathrm{NCX}}$ value was set to 2. To adjust the $\mathrm{Ca}^{2+}$ recirculation fraction to a physiological level (see Table 2), we reduced the scaling factor for the total current $k_{\mathrm{NCX}}$ to $125 \mathrm{pA} / \mathrm{pF}$.

\section{Contractile Element}

The contractile element of the model is based on the E-C coupling model published by Cortassa et al. [54]. That is, we implemented equations A81 and A96-121 to our model. Since the Cortassa model is based on guinea pig data, we adjusted some of the parameters related to the myofilament $\mathrm{Ca}^{2+}$ sensitivity to obtain $\mathrm{Ca}^{2+}$ transient and contraction force characteristics (force at diastolic $\left[\mathrm{Ca}^{2+}\right.$, maximum amplitude of the force, and time-to-peak of the force) that are typical for mouse cardiac myocytes [21,22]. Parameter modifications are presented in Table 3.

\section{Authors' contributions}

JTK implemented the regulatory mechanisms of the model, carried out the in silico experiments and data analysis and drafted the manuscript. TK implemented the electrophysiology part of the model and helped to draft the manuscript. JT implemented the contractile element part of the model. MW participated in the design and coordination of the study and helped to draft the manuscript. PT designed the study and drafted the manuscript. All authors read and approved the final manuscript.

\section{Acknowledgements}

The authors are grateful to Dr. Mikko Vähäsöyrinki from the Department of Physical Sciences and Sandra L. Hänninen from the Institute of Biomedicine, University of Oulu, for their comments and careful reading of the manuscript.

This work was supported by Sigrid Juselius Foundation (MW, PT), Finnish Heart Foundation (MW, PT, TK, JTK), Orion-Farmos Research Foundation (TK), Oulu University Scholarship Foundation (JTK) and Academy of Finland (MW, PT).

\section{References}

I. Bers DM: Cardiac excitation-contraction coupling. Nature 2002, 4I 5: I 98-205.

2. DeSantiago J, Maier LS, Bers DM: Frequency-dependent acceleration of relaxation in the heart depends on CaMKII, but not phospholamban. J Mol Cell Cardiol 2002, 34:975-984.

3. Molkentin JD, Dorn GW: Cytoplasmic signaling pathways that regulate cardiac hypertrophy. Annual Review of Physiology 200I, 63:391-426.

4. Frey N, Olson EN: Cardiac hypertrophy: The good, the bad and the ugly. Annual Review of Physiology 2003, 65:45-79.

5. Sjaastad I, Wasserstrom JA, Sejersted OM: Heart failure - a challenge to our current concepts of excitation-contraction coupling. Journal of Physiology-London 2003, 546:33-47.

6. Luo WS, Grupp IL, Harrer J, Ponniah S, Grupp G, Duffy JJ, Doetschman T, Kranias EG: Targeted Ablation of the Phospholamban Gene Is Associated with Markedly Enhanced MyocardialContractility and Loss of Beta-Agonist Stimulation. Circulation Research 1994, 75:40I-409.

7. Meyer M, Dillman WH: Sarcoplasmic reticulum $\mathbf{C a}^{2+}$-ATPase overexpression by adenovirus mediated gene transfer and in transgenic mice. Cardiovascular Research 1998, 37:360-366.

8. Molkentin JD, Lu JR, Antos CL, Markham B, Richardson J, Robbins J, Grant SR, Olson EN: A calcineurin-dependent transcriptional pathway for cardiac hypertrophy. Cell 1998, 93:215-228.

9. Zhang T, Maier LS, Dalton ND, Miyamoto S, Ross J, Bers DM, Brown $\mathrm{JH}$ : The delta(C) isoform of CaMKII is activated in cardiac hypertrophy and induces dilated cardiomyopathy and heart failure. Circulation Research 2003, 92:912-919.

10. Witcher DR, Kovacs RJ, Schulman H, Cefali DC, Jones LR: Unique Phosphorylation Site on the Cardiac Ryanodine Receptor Regulates Calcium-Channel Activity. Journal of Biological Chemistry 1991, 266: I I|44-III52.

II. Xu AD, Netticadan T, Jones DL, Narayanan N: Serine phosphorylation of the sarcoplasmic reticulum $\mathrm{Ca}^{2+}$-ATPase in the intact beating rabbit heart. Biochemical and Biophysical Research Communications 1999, 264:24I-246.

12. MacLennan DH, Kranias EG: Phospholamban: A crucial regulator of cardiac contractility. Nature Reviews Molecular Cell Biology 2003, 4:566-577.

13. Simmerman HK, Collins JH, Theibert JL, Wegener AD, Jones LR: Sequence analysis of phospholamban. Identification of phos- 
phorylation sites and two major structural domains. J Biol Chem 1986, 26I: |3333-|334I.

14. Dzhura I, Wu Y, Colbran RJ, Balser JR, Anderson ME: Calmodulin kinase determines calcium-dependent facilitation of L-type calcium channels. Nat Cell Biol 2000, 2:173-177.

15. Wu YJ, Dzhura I, Colbran RJ, Anderson ME: Calmodulin kinase and a calmodulin-binding 'IQ' domain facilitate L-type $\mathbf{C a}^{2+}$ current in rabbit ventricular myocytes by a common mechanism. Journal of Physiology-London 200I, 535:679-687.

16. De Koninck P, Schulman H: Sensitivity of CaM kinase II to the frequency of $\mathrm{Ca}^{2+}$ oscillations. Science 1998, 279:227-230.

17. Tavi P, Allen DG, Niemela P, Vuolteenaho O, Weckstrom M, Westerblad H: Calmodulin kinase modulates $\mathrm{Ca}^{2+}$ release in mouse skeletal muscle. Journal of Physiology-London 2003, 55 1:5-12.

18. Bassani RA, Mattiazzi A, Bers DM: Camkii Is Responsible for Activity-Dependent Acceleration of Relaxation in Rat Ventricular Myocytes. American Journal of Physiology-Heart and Circulatory Physiology 1995, 37:H703-H7I2.

19. Li L, Chu GX, Kranias EG, Bers DM: Cardiac myocyte calcium transport in phospholamban knockout mouse: relaxation and endogenous CaMKII effects. American Journal of PhysiologyHeart and Circulatory Physiology 1998, 43:HI335-HI347.

20. Maier LS, Zhang T, Chen L, DeSantiago J, Brown JH, Bers DM: Transgenic CaMKII delta(C) overexpression uniquely alters cardiac myocyte $\mathrm{Ca}^{2+}$ handling - Reduced SR $\mathrm{Ca}^{2+}$ load and activated SR Ca ${ }^{2+}$ release. Circulation Research 2003, 92:904-9II.

21. Ito K, Yan X, Tajima M, Su Z, Barry WH, Lorell BH: Contractile reserve and intracellular calcium regulation in mouse myocytes from normal and hypertrophied failing hearts. Circulation Research 2000, 87:588-595.

22. Stuyvers BD, McCulloch AD, Guo JQ, Duff $H$, ter Keurs HED] Effect of stimulation rate, sarcomere length and $\mathrm{Ca}^{2+}$ on force generation by mouse cardiac muscle. Journal of PhysiologyLondon 2002, 544:8I7-830.

23. Stull LB, Leppo MK, Marban E, Janssen PML: Physiological determinants of contractile force generation and calcium handling in mouse myocardium. Journal of Molecular and Cellular Cardiology 2002, 34:1367-1376

24. Tavi P, Hansson A, Zhang SJ, Larsson NG, Westerblad H: Abnorma $\mathrm{Ca}^{2+}$ release and catecholamine-induced arrhythmias in mitochondrial cardiomyopathy. Human Molecular Genetics 2005, | 4: 1069-1076.

25. Tavi P, Sjogren M, Lunde PK, Zhang SJ, Abbate F, Vennstrom B, Westerblad $\mathrm{H}$ : Impaired $\mathrm{Ca}^{2+}$ handling and contraction in cardiomyocytes from mice with a dominant negative thyroid hormone receptor alpha(I). Journal of Molecular and Cellular Cardiology 2005, 38:655-663.

26. D'Alcantara P, Schiffmann SN, Swillens S: Bidirectional synaptic plasticity as a consequence of interdependent $\mathrm{Ca}^{2+}$-controlled phosphorylation and dephosphorylation pathways. Eur J Neurosci 2003, I 7:252।-2528.

27. Santana LF, Kranias EG, Lederer WJ: Calcium sparks and excitation-contraction coupling in phospholamban-deficient mouse ventricular myocytes. Journal of Physiology-London 1997. 503:21-29.

28. Wolska BM, Stojanovic MO, Luo WS, Kranias EG, Solaro RJ: Effect of ablation of phospholamban on dynamics of cardiac myocyte contraction and intracellular $\mathrm{Ca}^{2+}$. American Journal of Physiology-Cell Physiology 1996, 40:C39I-C397.

29. Frank K, Tilgmann C, Shannon TR, Bers DM, Kranias EG: Regulatory role of phospholamban in the efficiency of cardiac sarcoplasmic reticulum $\mathrm{Ca}^{2+}$ transport. Biochemistry 2000, 39:14176-14182.

30. Mattiazzi A, Mundina-Weilenmann C, Chu GX, Vittone L, Kranias E: Role of phospholamban phosphorylation on $\operatorname{Thr}(17)$ in cardiac physiological and pathological conditions. Cardiovascular Research 2005, 68:366-375.

31. Shannon TR, Chu GX, Kraniass EG, Bers DM: Phospholamban decreases the energetic efficiency of the Sarcoplasmic reticulum Ca pump. Journal of Biological Chemistry 200I, 276:7I 95-720I.

32. Huser J, Bers DM, Blatter LA: Subcellular properties of $\left[\mathrm{Ca}^{2+}\right]_{i}$ transients in phospholamban-deficient mouse ventricular cells. American Journal of Physiology-Heart and Circulatory Physiology 1998, 43:HI800-HI8II.

33. Chu G, Luo W, Slack JP, Tilgmann C, Sweet WE, Spindler M, Saupe $\mathrm{KW}$, Boivin GP, Moravec CS, Matlib MA, et al:: Compensatory mechanisms associated with the hyperdynamic function of phospholamban-deficient mouse hearts. Circ Res 1996, 79:1064-1076.

34. Masaki H, Sato Y, Luo WS, Kranias EG, Yatani A: Phospholamban deficiency alters inactivation kinetics of $L$-type $\mathbf{C a}^{2+}$ channels in mouse ventricular myocytes. American Journal of PhysiologyHeart and Circulatory Physiology 1997, 41:H606-H6I2

35. Yuan WL, Bers DM: Ca-Dependent Facilitation of Cardiac Ca Current Is Due to Ca-Calmodulin-Dependent ProteinKinase. American Journal of Physiology 1994, 267:H982-H993.

36. Anderson ME: Calmodulin kinase and L-type calcium channels: A recipe for arrhythmias? Trends in Cardiovascular Medicine 2004, 14:|52-16|.

37. Maier LS: CaMKII delta overexpression in hypertrophy and heart failure: cellular consequences for excitation-contraction coupling. Brazilian Journal of Medical and Biological Research 2005, 38: $1293-1302$.

38. Maier LS, Bers DM: Role of Ca2+/calmodulin-dependent protein kinase (CaMK) in excitation-contraction coupling in the heart. Cardiovascular Research 2007, 73:63I-640.

39. Zhang $\mathrm{T}$, Brown JH: Role of $\mathbf{C a}^{2+} /$ calmodulin-dependent protein kinase II in cardiac hypertrophy and heart failure. Cardiovascular Research 2004, 63:476-486.

40. Kohlhaas M, Zhang T, Seidler T, Zibrova D, Dybkova N, Steen A, Wagner S, Chen L, Brown JH, Bers DM, Maier LS: Increased sarcoplasmic reticulum calcium leak but unaltered Contractility by acute CaMKII overexpression in isolated rabbit cardiac myocytes. Circulation Research 2006, 98:235-244.

4I. Tavi P, Pikkarainen S, Ronkainen J, Niemela P, Ilves M, Weckstrom M, Vuolteenaho O, Bruton J, Westerblad H, Ruskoaho H: Pacinginduced calcineurin activation controls cardiac $\mathrm{Ca}^{2+}$ signalling and gene expression. Journal of Physiology-London 2004, 554:309-320.

42. Bhalla US, lyengar R: Robustness of the bistable behavior of a biological signaling feedback loop. Chaos 200I, I I:22I-226.

43. Tobimatsu T, Fujisawa H: Tissue-specific expression of four types of rat calmodulin-dependent protein kinase II mRNAs. J Biol Chem 1989, 264: 17907-I79/2.

44. Chiba H, Schneider N, Matsuoka S, Noma A: A simulation study on the activation of cardiac CaMKII \{delta\}-isoform and its regulation by phosphatases. Biophysical Journal 2008, 95:2139-2149.

45. Saucerman JJ, Bers DM: Calmodulin Mediates Differential Sensitivity of CaMKII and Calcineurin to Local Ca2+ in Cardiac Myocytes. 2008, 95:4597-46I2.

46. Bhalla US, lyengar R: Emergent properties of networks of biological signaling pathways. Science 1999, 283:38I-387.

47. Toyofuku T, Kurzydlowski K, Narayanan N, Maclennan DH: Identification of Ser(38) as the Site in Cardiac Sarcoplasmic-Reticulum Ca ${ }^{2+}$-Atpase That Is Phosphorylated by $\mathrm{Ca}^{2+}$ Calmodulin-Dependent Protein-Kinase. Journal of Biological Chemistry 1994, 269:26492-26496.

48. Maier LS, Bers DM, Brown JH: Calmodulin and $\mathrm{Ca}^{2+} / \mathbf{c a l m o d u l i n}$ kinases in the heart - Physiology and pathophysiology. Cardiovascular Research 2007, 73:629-630.

49. Hanson PI, Schulman H: Inhibitory Autophosphorylation of Multifunctional $\mathrm{Ca}^{2+}$ Calmodulin-Dependent Protein-Kinase Analyzed by Site-Directed Mutagenesis. Journal of Biological Chemistry 1992, 267:17216-17224.

50. Ai X, Curran JW, Shannon TR, Bers DM, Pogwizd SM: Ca ${ }^{2+} /$ calmodulin-dependent protein kinase modulates cardiac ryanodine receptor phosphorylation and sarcoplasmic reticulum $\mathrm{Ca}^{2+}$ leak in heart failure. Circulation Research 2005, 97: I3 |4-1322.

5I. Slack JP, Grupp IL, Dash R, Holder D, Schmidt A, Gerst MJ, Tamura T, Tilgmann C, James PF, Johnson R, et al:: The Enhanced Contractility of the Phospholamban-deficient Mouse Heart Persists with Aging. Journal of Molecular and Cellular Cardiology 200I, 33: $1031-1040$.

52. Richard S, Perrier E, Fauconnier J, Perrier R, Pereira L, Gomez AM, Benitah JP: 'Ca2+-induced $\mathbf{C a 2 +}$ entry' or how the L-type $\mathbf{C a 2 +}$ channel remodels its own signalling pathway in cardiac cells. Progress in Biophysics \& Molecular Biology 2006, 90: I I8-135.

53. Bondarenko VE, Szigeti GP, Bett GCL, Kim SJ, Rasmusson RL: Computer model of action potential of mouse ventricular myocytes. American Journal of Physiology-Heart and Circulatory Physiology 2004, 287: HI378-HI403. 
54. Cortassa S, Aon MA, O'Rourke B, Jacques R, Tseng HJ, Marban E, Winslow RL: A computational model integrating electrophysiology, contraction, and mitochondrial bioenergetics in the ventricular myocyte. Biophysical Journal 2006, 91:I564-I 589.

55. Luo CH, Rudy Y: A Dynamic-Model of the Cardiac Ventricular Action-Potential .I. Simulations of Ionic Currents and Concentration Changes. Circulation Research 1994, 74:107|-1096.

56. ten Tusscher KHW], Noble D, Noble PJ, Panfilov AV: A model for human ventricular tissue. American Journal of Physiology-Heart and Circulatory Physiology 2004, 286:HI573-HI589.

57. Antoons G, Mubagwa K, Nevelsteen I, Sipido KR: Mechanisms underlying the frequency dependence of contraction and $\left[\mathrm{Ca}^{2+}\right]_{\mathrm{i}}$ transients in mouse ventricular myocytes. Journal of Physiology-London 2002, 543:889-898.

58. Guo J, Zhan S, Somers J, Westenbroek RE, Catterall WA, Roach DE, Sheldon RS, Lees-Miller JP, Li P, Shimoni Y, Duff HJ: Decrease in density of I-Na is in the common final pathway to heart block in murine hearts overexpressing calcineurin. American Journal of Physiology-Heart and Circulatory Physiology 2006, 29 I:H2669-H2679.

59. Brunet S, Aimond F, Li HL, Guo WN, Eldstrom J, Fedida D, Yamada $\mathrm{KA}$, Nerbonne JM: Heterogeneous expression of repolarizing, voltage-gated $\mathrm{K}^{+}$currents in adult mouse ventricles. Journal of Physiology-London 2004, 559:103-120.

60. Petrashevskaya NN, Bodi I, Koch SE, Akhter SA, Schwartz A: Effects of alpha(I)-adrenergic stimulation on normal and hypertrophied mouse hearts. Relation to caveolin-3 expression. Cardiovascular Research 2004, 63:561-572.

61. Williams IA, Allen DG: Intracellular calcium handling in ventricular myocytes from mdx mice. Am J Physiol Heart Circ Physiol 2007, 292: H846-855.

62. Shannon TR, Wang F, Bers DM: Regulation of cardiac sarcoplasmic reticulum ca release by luminal $[\mathrm{Ca}]$ and altered gating assessed with a mathematical model. Biophysical Journal 2005 , 89:4096-4II0

63. Wehrens XHT, Lehnart SE, Reiken SR, Marks AR: $\mathbf{C a}^{2+} /$ calmodulin- $^{2}$ dependent protein kinase II phosphorylation regulates the cardiac ryanodine receptor. Circulation Research 2004 , 94:E6I-E70.

64. Keizer J, Levine L: Ryanodine receptor adaptation and $\mathbf{C a}^{2+}$ induced $\mathrm{Ca}^{2+}$ release-dependent $\mathrm{Ca}^{2+}$ oscillations. Biophysical Journal 1996, $71: 3477-3487$.

65. Grueter CE, Abiria SA, Dzhura I, Wu Y, Ham AJ, Mohler PJ, Anderson ME, Colbran RJ: L-type Ca2+ channel facilitation mediated by phosphorylation of the beta subunit by CaMKII. Mol Cell 2006 23:64I-650.

66. Yao AS, Su Z, Nonaka A, Zubair I, Lu LY, Philipson KD, Bridge JHB, Barry WH: Effects of overexpression of the $\mathrm{Na}^{+}-\mathrm{Ca}^{2+}$ exchanger on $\left[\mathrm{Ca}^{2+}\right]$ transients in murine ventricular myocytes. Circulation Research 1998, 82:657-665.

67. Despa S, Bossuyt J, Han F, Ginsburg KS, Jia LG, Kutchai H, Tucker AL Bers DM: Phospholemman-phosphorylation mediates the beta-adrenergic effects on $\mathrm{Na} / \mathrm{K}$ pump function in cardiac myocytes. Circulation Research 2005, 97:252-259.

68. Brouillette J, Clark RB, Giles WR, Fiset C: Functional properties of $\mathrm{K}^{+}$currents in adult mouse ventricular myocytes. Journal of Physiology-London 2004, 559:777-798.

69. Guo W, Xu H, London B, Nerbonne JM: Molecular basis of transient outward $\mathrm{K}+$ current diversity in mouse ventricular myocytes. J Physiol 1999, 52 I:587-599.

70. Thomas SP, Kucera JP, Bircher-Lehmann L, Rudy Y, Saffitz JE, Kleber AG: Impulse propagation in synthetic strands of neonatal cardiac myocytes with genetically reduced levels of connexin43. Circulation Research 2003, 92:1209-1216.

71. MacDonell KL, Severson DL, Giles WR: Depression of excitability by sphingosine I-phosphate in rat ventricular myocytes. Am J Physiol 1998, 275: $\mathrm{H} 229$ I-2299.

72. Wier WG, Egan TM, Lopezlopez JR, Balke CW: Local-Control of Excitation-Contraction Coupling in Rat-Heart Cells. Journal of Physiology-London 1994, 474:463-471.

73. Brittsan AG, Ginsburg KS, Chu GX, Yatani A, Wolska BM, Schmidt AG, Asahi M, MacLennan DH, Bers DM, Kranias EG: Chronic SR $\mathrm{Ca}^{2+}$-ATPase inhibition causes adaptive changes in cellular $\mathrm{Ca}^{2+}$ transport. Circulation Research 2003, 92:769-776.

74. Knollmann BC, Kirchhof P, Sirenko SG, Degen H, Greene AE, Schober T, Mackow JC, Fabritz L, Potter JD, Morad M: Familial hypertrophic cardiomyopathy-linked mutant troponin $T$ causes stress-induced ventricular tachycardia and $\mathrm{Ca}^{2+}$ dependent action potential remodeling. Circulation Research 2003, 92:428-436.

75. Shannon TR, Ginsburg KS, Bers DM: Reverse mode of the sarcoplasmic reticulum calcium pump and load-dependent cytosolic calcium decline in voltage-clamped cardiac ventricular myocytes. Biophysical Journal 2000, 78:322-333.

76. Hund TJ, Kucera JP, Otani NF, Rudy Y: Ionic charge conservation and long-term steady state in the Luo-Rudy dynamic cell model. Biophysical Journal 200I, 8I:3324-333I.

77. The DOCQS Database [http://doqcs.ncbs.res.in/]

78. Hund TJ, Rudy Y: Rate dependence and regulation of action potential and calcium transient in a canine cardiac ventricular cell model. Circulation 2004, I I0:3 168-3174.

79. Jafri MS, Rice J], Winslow RL: Cardiac $\mathbf{C a}^{2+}$ dynamics: The roles of ryanodine receptor adaptation and sarcoplasmic reticulum load. Biophysical Journal |998, 74: | |49-1 | 68.

80. Odermatt A, Kurzydlowski K, MacLennan DH: The V-max of the $\mathrm{Ca}^{2+}$-ATPase of cardiac sarcoplasmic reticulum (SERCA2a) is not altered by $\mathrm{Ca}^{2+} /$ Calmodulin dependent phosphorylation or by interaction with phospholamban. Journal of Biological Chemistry 1996, $271:$ | 14206-14213.

81. Bers DM: Excitation-contraction coupling and cardiac contractile force 2nd edition. Dordrecht; Boston: Kluwer Academic Publishers; 200I.

82. Hashambhoy YL, Winslow RL, Greenstein JL: CaMKII-Induced Shift in Modal Gating Explains L-Type $\mathrm{Ca}^{2+}$ Current Facilitation: A Modeling Study. Biophysical Journal 2009, 96: 1770-1785.

83. Li L, Satoh H, Ginsburg KS, Bers DM: The effect of $\mathbf{C a}^{2+}$-calmodulin-dependent protein kinase II on cardiac excitation-contraction coupling in ferret ventricular myocytes. Journal of Physiology-London 1997, 50 I:I7-31.

84. Zuhlke RD, Pitt GS, Deisseroth K, Tsien RW, Reuter H: Calmodulin supports both inactivation and facilitation of L-type calcium channels. Nature 1999, 399:159-162.

85. Gao L, Blair LAC, Marshall J: CaMKII-independent effects of KN93 and its inactive analog KN 92: Reversible inhibition of L-type calcium channels. Biochemical and Biophysical Research Communications 2006, 345:1606-1610.

86. Wu YJ, Colbran RJ, Anderson ME: Calmodulin kinase is a molecular switch for cardiac excitation-contraction coupling. Proceedings of the National Academy of Sciences of the United States of America 200I, 98:2877-288I.

87. Wu YJ, Temple J, Zhang R, Dzhura I, Zhang W, Trimble R, Roden DM, Passier R, Olson EN, Colbran RJ, Anderson ME: Calmodulin kinase II and arrhythmias in a mouse model of cardiac hypertrophy. Circulation 2002, 106: 1288-1293.

Publish with Bio Med Central and every scientist can read your work free of charge

"BioMed Central will be the most significant development for disseminating the results of biomedical research in our lifetime. "

Sir Paul Nurse, Cancer Research UK

Your research papers will be:

- available free of charge to the entire biomedical community

- peer reviewed and published immediately upon acceptance

- cited in PubMed and archived on PubMed Central

- yours - you keep the copyright 